\title{
Daytime SABER/TIMED observations of water vapor in the mesosphere: retrieval approach and first results
}

\author{
A. G. Feofilov ${ }^{1,2}$, A. A. Kutepov ${ }^{1,2}$, W. D. Pesnell ${ }^{2}$, R. A. Goldberg ${ }^{2}$, B. T. Marshall ${ }^{3}$, L. L. Gordley ${ }^{3}$, \\ M. García-Comas ${ }^{4}$, M. López-Puertas ${ }^{4}$, R. O. Manuilova ${ }^{5}$, V. A. Yankovsky ${ }^{5}$, S. V. Petelina ${ }^{6}$, and J. M. Russell III $^{7}$ \\ ${ }^{1}$ The Catholic University of America, 620 Michigan Ave., Washington D.C. 20064, USA \\ ${ }^{2}$ NASA Goddard Space Flight Center, Mailcode 674, Greenbelt Rd., Greenbelt, MD 20771, USA \\ ${ }^{3}$ GATS Inc., 1164 Canon Blvd., Suite 101, Newport News, VA 23606, USA \\ ${ }^{4}$ Instituto de Astrofísica de Andalucía (CSIC), C/Camino Bajo de Huetor, 50, Granada, 18008, Spain \\ ${ }^{5}$ Institute for Physics, St.Petersburg State University, Ulianovskaja, 1, St. Petersburg, 198904, Russia \\ ${ }^{6}$ La Trobe University, Victoria, 3086, Australia \\ ${ }^{7}$ Hampton University, Hampton, VA 23668, USA
}

Received: 6 May 2009 - Published in Atmos. Chem. Phys. Discuss.: 26 June 2009

Revised: 5 October 2009 - Accepted: 12 October 2009 - Published: 2 November 2009

\begin{abstract}
This paper describes a methodology for water vapor retrieval in the mesosphere-lower thermosphere (MLT) using $6.6 \mu \mathrm{m}$ daytime broadband emissions measured by SABER, the limb scanning infrared radiometer on board the TIMED satellite. Particular attention is given to accounting for the non-local thermodynamic equilibrium (non-LTE) nature of the $\mathrm{H}_{2} \mathrm{O} 6.6 \mu \mathrm{m}$ emission in the MLT. The nonLTE $\mathrm{H}_{2} \mathrm{O}\left(v_{2}\right)$ vibrational level populations responsible for this emission depend on energy exchange processes within the $\mathrm{H}_{2} \mathrm{O}$ vibrational system as well as on interactions with vibrationally excited states of the $\mathrm{O}_{2}, \mathrm{~N}_{2}$, and $\mathrm{CO}_{2}$ molecules. The rate coefficients of these processes are known with large uncertainties that undermines the reliability of the $\mathrm{H}_{2} \mathrm{O}$ retrieval procedure. We developed a methodology of finding the optimal set of rate coefficients using the nearly coincidental solar occultation $\mathrm{H}_{2} \mathrm{O}$ density measurements by the ACEFTS satellite and relying on the better signal-to-noise ratio of SABER daytime $6.6 \mu \mathrm{m}$ measurements. From this comparison we derived an update to the rate coefficients of the three most important processes that affect the $\mathrm{H}_{2} \mathrm{O}\left(v_{2}\right)$ populations in the MLT: a) the vibrational-vibrational (V-V) exchange between the $\mathrm{H}_{2} \mathrm{O}$ and $\mathrm{O}_{2}$ molecules; b) the vibrationaltranslational (V-T) process of the $\mathrm{O}_{2}(1)$ level quenching by collisions with atomic oxygen, and c) the $\mathrm{V}-\mathrm{T}$ process of the $\mathrm{H}_{2} \mathrm{O}(010)$ level quenching by collisions with $\mathrm{N}_{2}, \mathrm{O}_{2}$, and $\mathrm{O}$. Using the advantages of the daytime retrievals in the MLT, which are more stable and less susceptible to uncertainties
\end{abstract}

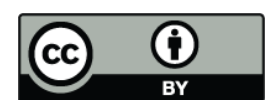

Correspondence to: A. G. Feofilov (artem-feofilov@cua-nasa-gsfc.info) of the radiance coming from below, we demonstrate that applying the updated $\mathrm{H}_{2} \mathrm{O}$ non-LTE model to the SABER daytime radiances makes the retrieved $\mathrm{H}_{2} \mathrm{O}$ vertical profiles in 50-85 km region consistent with climatological data and model predictions. The $\mathrm{H}_{2} \mathrm{O}$ retrieval uncertainties in this approach are about $10 \%$ at and below $70 \mathrm{~km}, 20 \%$ at $80 \mathrm{~km}$, and $30 \%$ at $85 \mathrm{~km}$ altitude.

\section{Introduction}

Water vapor is one of the key components of the middle atmosphere that influences the composition and energy budget of this region in a number of ways. Being a source for chemically active constituents, such as $\mathrm{OH}, \mathrm{O}\left({ }^{1} \mathrm{D}\right), \mathrm{H}_{2}$, and $\mathrm{H}$ (Brasseur and Solomon, 2005), it participates in so called "zero-cycle" reactions where the absorption of solar shortwave radiation leads to $\mathrm{H}_{2} \mathrm{O}$ photodissociation with subsequent recombination in a number of processes that result in heating of the atmosphere (Sonnemann et al., 2005). Though direct radiative cooling and heating effects of water vapor in rotational and vibrational transitions are small in comparison to that of $\mathrm{CO}_{2}$ and $\mathrm{O}_{3}$, the water vapor concentration controls the concentration of ozone that, in turn, affects mesospheric cooling. The long photochemical lifetime of $\mathrm{H}_{2} \mathrm{O}$ makes it an excellent tracer for atmospheric dynamics (Peter, 1998) enabling one to follow the atmospheric transport effects up to $80-85 \mathrm{~km}$ altitude. The existence of water molecules at sufficiently low temperatures near the polar summer mesopause leads to the nucleation of ice particles in the MLT region (e.g. Rapp and Thomas, 2006, and references

Published by Copernicus Publications on behalf of the European Geosciences Union. 
therein). These particles are responsible for such phenomena as noctilucent clouds (NLCs) and polar mesospheric summer echoes (PMSEs, see also Appendix A for the abbreviations not explained in the text for readability's sake). Due to high sensitivity to local kinetic temperatures, the NLC and PMSE phenomena can be used as temperature probes for these regions (e.g. Lübken et al., 2007; Petelina and Zasetsky, 2009) and as possible indicators of climate change (e.g. Thomas, 2003). NLCs have also been used as tracers of Shuttle rocket engine exhausts when an extraordinary amount of water was injected into the atmosphere causing an increase in NLC brightness (Siskind et al., 2003; Stevens et al., 2003, 2005).

Water vapor measurements in the MLT region have been performed since the 1970s utilizing ground- and aircraft-based microwave measurements (Croom et al., 1977; Bevilacqua et al., 1983; Hartogh et al., 1995; see also references in Brasseur and Solomon, 2005, Sect. 4.1.1). Spaceborne measurements of the water vapor altitude distributions started in 1978 with the launch of the Nimbus-7 spacecraft observatory that utilized the SAMS (Drummond et al., 1980) and the LIMS (Gille et al., 1980) instruments for water vapor observations. Since then water vapor has been measured by a number of space experiments: HALOE (Russell et al., 1993), ISAMS (Taylor et al., 1993), ATMOS (Gunson et al., 1996), CRISTA-1,2 (Offermann et al., 1999; Grossmann et al., 2002), and others. Six satellite-borne instruments are currently performing water vapor measurements in the upper atmosphere: the ACE-FTS/Scisat-1 (Bernath et al., 2005) and SOFIE/AIM (Gordley et al., 2009) instruments use an occultation technique, while MLS/Aura (Waters et al., 1999), SMR/Odin (Murtagh et al., 2002), SABER/TIMED (Russell et al., 1999), and MIPAS/Envisat (Fischer et al., 2008) measure atmospheric emission in the limb.

Most of the methods used for inversion of infrared radiation data obtained in the limb viewing geometry are based on the solution of the radiative transfer problem under the assumption of local thermodynamic equilibrium (LTE) (Gille and Russell, 1984; Barnet, 1987). However, above about $55 \mathrm{~km}$ altitude the vibrational $\mathrm{H}_{2} \mathrm{O}\left(\nu_{2}\right)$ levels, which give rise to the bands providing the main contribution to the $6.6 \mu \mathrm{m}$ SABER channel, are out of LTE (López-Puertas and Taylor, 2001). As a result, water vapor density retrievals in the MLT require solving the non-LTE problem for the populations of $\mathrm{H}_{2} \mathrm{O}$ vibrational levels. Non-LTE also complicates the retrieval process by making the entire problem non-local in altitudes, with the variation of the $\mathrm{H}_{2} \mathrm{O}$ density at one altitude affecting the $\mathrm{H}_{2} \mathrm{O}$ levels populations at other altitudes, especially in the MLT region. For these kinds of tasks, the forward fitting iterative approach is preferable (Gusev, 2003) enabling one to adjust the non-LTE populations at different altitudes to an iteratively changing profile of the retrieved atmospheric constituent.

In this paper we describe the SABER instrument, its $6.6 \mu \mathrm{m}$ limb emission observation of the MLT (Sect. 2), and the current status of the $\mathrm{H}_{2} \mathrm{O}$ non-LTE models (Sect. 3). Section 4 presents the computer code package ALI-ARMS and the retrieval algorithm applied in this study. In Sect. 5 we present a sensitivity study of the non-LTE model to the variation of a number of rate coefficients of energy exchanges processes influencing the populations of $\mathrm{H}_{2} \mathrm{O}$ vibrational levels during daytime. We demonstrate how the broadband $6.6 \mu \mathrm{m}$ emission simulations required for the $\mathrm{H}_{2} \mathrm{O}$ density retrieval are affected by the uncertainties in available rate coefficients. Using the simultaneous common volume measurements performed by the SABER instrument and ACE-FTS occultation experiment which is not affected by non-LTE effects, we illustrate that a revision of certain rate coefficients is required for an adequate interpretation of broadband $6.6 \mu \mathrm{m}$ non-LTE $\mathrm{H}_{2} \mathrm{O}$ emissions. In this section we describe the approach for the rate coefficients fitting and suggest an update to values of these rate coefficients. In Sect. 6 we present the results of preliminary SABER $\mathrm{H}_{2} \mathrm{O}$ mixing ratio retrievals obtained by applying the updated $\mathrm{H}_{2} \mathrm{O}$ non-LTE model and show that these retrievals are in a good agreement with other observations and models. Section 7 bridges results obtained with the ALI-ARMS research code and those obtained with this code to the operational retrieval. The latter will be used to produce $\mathrm{H}_{2} \mathrm{O}$ distributions in the next release of SABER data. This section also describes the SABER Operational Processing Code (SOPC) that is based on the GRANADA research code and discusses the retrieval uncertainties linked with the optimization of the research code for operational uses. The main results of the paper are summarized in the Sect. 8 .

\section{SABER instrument on the TIMED satellite}

The TIMED satellite was launched on 7 December 2001 into a $74.1^{\circ}$ inclined $625 \mathrm{~km}$ orbit with a period of $1.7 \mathrm{~h}$. The TIMED mission is focused on the energetics and dynamics of the mesosphere-lower thermosphere region $(60-180 \mathrm{~km})$ (Yee et al., 1999). SABER, one of four instruments on TIMED, is a 10-channel broadband limb-scanning infrared radiometer covering the spectral range from $1.27 \mu \mathrm{m}$ to $17 \mu \mathrm{m}$. SABER provides vertical profiles of kinetic temperature, pressure, ozone, carbon dioxide, water vapor, atomic oxygen, atomic hydrogen and volume emission rates in the $\mathrm{NO}(5.3 \mu \mathrm{m})$ and $\mathrm{OH}$ Meinel and $\mathrm{O}_{2}\left({ }^{1} \Delta\right)$ bands. The vertical instantaneous field of view of the instrument is approximately $2.0 \mathrm{~km}$ at $60 \mathrm{~km}$ altitude, the vertical sampling interval is $\sim 0.4 \mathrm{~km}$, and the atmosphere is scanned from below the surface up to $400 \mathrm{~km}$ tangent height. The instrument performs one vertical scan every $53 \mathrm{~s}$, the scans are performed both in up- and downward directions. The latitudinal coverage is governed by a 60-day yaw cycle that allows observations of latitudes from $83^{\circ} \mathrm{S}$ to $52^{\circ} \mathrm{N}$ in the South viewing phase or from $53^{\circ} \mathrm{S}$ to $82^{\circ} \mathrm{N}$ in the North viewing phase. The instrument has been performing near-continuous measurements in this mode since 25 January 2002. 


\section{$3 \quad \mathrm{H}_{2} \mathrm{O}$ 6.6 $\mu \mathrm{m}$ radiance measured by SABER}

In the gas phase, water molecule vibrations involve combinations of symmetric stretch $\left(v_{1}\right)$, covalent bond bending $\left(v_{2}\right)$, and asymmetric stretch $\left(v_{3}\right)$ modes with the band strength ratio for the fundamental bands of the main $\mathrm{H}_{2} \mathrm{O}$ isotope being $0.07 / 1.50 / 1.00$ for the $v_{1}, v_{2}$, and $v_{3}$ vibrations, respectively (Goody and Young, 1995, and references therein; Rothman et al., 2005). The diagram in Fig. 1 shows the ground and various excited vibrational levels of $\mathrm{H}_{2} \mathrm{O}$ molecule up to $7445 \mathrm{~cm}^{-1}$. The levels are marked in accordance with the number of vibrational quanta $v_{1} v_{2} v_{3}$. The $6.6 \mu \mathrm{m}$ radiance measured in the water vapor channel of the SABER instrument arises from the optical transitions from vibrationally excited states with $\Delta v_{2}=1$, where $\Delta v_{2}$ denotes the change in the $v_{2}$ vibrational quanta number.

\subsection{LTE and non-LTE conditions in $\mathrm{H}_{2} \mathrm{O}$}

The interpretation of SABER $6.6 \mu \mathrm{m}$ limb radiance profiles requires the information on populations of the corresponding $\mathrm{H}_{2} \mathrm{O}$ vibrational levels at the altitudes of limb observations. In the lower atmosphere the frequency of inelastic molecular collisions is sufficiently high, so that these collisions overwhelm other population/depopulation mechanisms of the molecular vibrational levels. This leads to a local thermodynamic equilibrium, and the populations follow the Boltzmann distribution governed by the local kinetic temperature $T_{\text {kin. }}$. In the MLT, where the frequency of inelastic collisions is much lower than that at lower altitudes, other processes also influence the population of $\mathrm{H}_{2} \mathrm{O}$ vibrational levels. These include: a) the direct absorption of solar radiance by the $\mathrm{H}_{2} \mathrm{O}$ vibrational-rotational bands in the $1.4-6.3 \mu \mathrm{m}$ spectral region; b) absorption of the $6.6 \mu \mathrm{m}$ radiance coming from the warmer and denser lower atmosphere; c) vibrational-translational (V-T) energy exchanges by collisions with molecules and atoms of other atmospheric constituents; d) collisional vibrational-vibrational (V-V) energy exchange with other molecules. As a result, LTE no longer applies in this altitude region and the populations must be found by solving the self-consistent system of kinetic and radiative transfer equations, which express the balance relations between various excitation/de-excitation processes described above.

\subsection{Non-LTE model of $\mathrm{H}_{2} \mathrm{O}$}

In this work we use two non-LTE models of water vapor developed by different groups. The first one, with 7 vibrational levels and 10 ro-vibrational bands was developed by López-Puertas et al. (1995) and updated in the book by López-Puertas and Taylor (2001). The second one, with 14 vibrational levels and 33 ro-vibrational bands was developed by Manuilova et al. (2001). The levels included in the models are shown in Fig. 1 where the thick horizontal lines represent

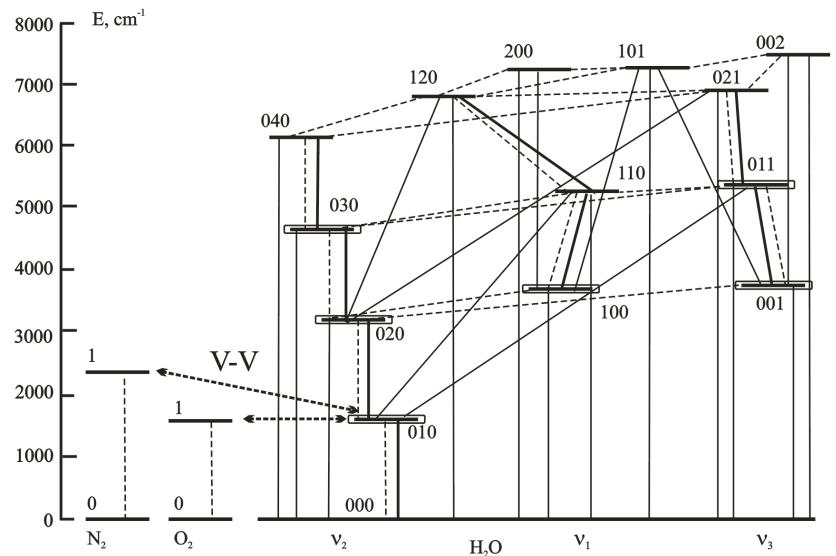

Fig. 1. Vibrational levels, $6.6 \mu \mathrm{m}$ optical transitions (thick solid lines), other optical transitions (thin solid lines), and V-V, V-T energy exchange processes (dashed lines) for $\mathrm{H}_{2} \mathrm{O}$ non-LTE model. Thick boxed lines correspond to an optimized set of levels used in SOPC.

the vibrational levels of $\mathrm{H}_{2} \mathrm{O}, \mathrm{O}_{2}$, and $\mathrm{N}_{2}$ molecules while the boxed thick lines refer to the $\mathrm{H}_{2} \mathrm{O}$ levels in the model of López-Puertas et al. (1995). The lowest vibrational levels of the $\mathrm{O}_{2}$ and $\mathrm{N}_{2}$ molecules coupled by $\mathrm{V}-\mathrm{V}$ exchange with those of $\mathrm{H}_{2} \mathrm{O}$ are also shown in Fig. 1. The dashed lines on Fig. 1 correspond to the $\mathrm{V}-\mathrm{V}$ and $\mathrm{V}-\mathrm{T}$ transitions listed in Table 1 (López-Puertas and Taylor, 2001; Manuilova et al., 2001). Thin solid lines show the optical transitions between $\mathrm{H}_{2} \mathrm{O}$ levels. Spectroscopic information for these transitions is taken from the HITRAN 2004 database (Rothman et al., 2005).

This work focuses on the daytime cases for two reasons. First, the daytime $6.6 \mu \mathrm{m}$ radiances measured by SABER are larger than the nighttime radiances. Thus larger SNR allows the $\mathrm{H}_{2} \mathrm{O}$ volume mixing ratio (VMR) retrieval up to $85-90 \mathrm{~km}$ altitude. Second, the more sophisticated daytime non-LTE model includes the effects of the nighttime model as a subset. During the day the $\mathrm{O}_{2}(1)$ level is populated by a complex chain of electronic-vibrational (E-V), V-V and V-T exchange processes involving the $\mathrm{O}_{2} / \mathrm{O}_{3}$ photolysis products $\mathrm{O}\left({ }^{1} \mathrm{D}\right), \mathrm{O}_{2}\left(b^{1} \Sigma_{g}^{+}, \mathrm{v}\right), \mathrm{O}_{2}\left(\mathrm{a}^{1} \Delta_{g}, \mathrm{v}\right)$, and $\mathrm{O}_{2}\left(\mathrm{X}^{3} \Sigma^{-}\right.$, v). The most detailed kinetic model of the $\mathrm{O}_{2} / \mathrm{O}_{3}$ photolysis products was presented by Yankovsky and Manuilova (2006), hereafter YM2006. In this model, the quantum yield of $\mathrm{O}_{2}(1)$ molecules per $\mathrm{O}_{3}$ photolysis event $(\varepsilon)$ depends on the altitude (see also Fig. 3 in Manuilova et al., 2001, and its update in Yankovsky and Babaev, 2009), while the model by López-Puertas and Taylor (2001) utilizes the constant value $\varepsilon=4$ at all altitudes. Another aspect of coupling the system of $\mathrm{H}_{2} \mathrm{O}$ levels with the $\mathrm{O}_{2}(1)$ level is the interaction of the latter with the second $v_{2}$ state of $\mathrm{CO}_{2}$ through $\mathrm{V}-\mathrm{V}$ exchange. Depending on the season and location, this level is in non-LTE above $70-80 \mathrm{~km}$ altitude, and the calculation of its population requires solving the $\mathrm{CO}_{2}$ non-LTE problem 
Table 1. Collisional processes involved in the nominal $\mathrm{H}_{2} \mathrm{O}$ non-LTE model.

\begin{tabular}{|c|c|c|c|c|}
\hline $\mathrm{N}$ & Process & Type & Rate coefficient, $\mathrm{cm}^{3} \mathrm{~s}^{-1}$ & References \\
\hline 1 & $\mathrm{H}_{2} \mathrm{O}\left(v_{1} ; v_{2} ; v_{3}\right)+\mathrm{O}_{2}(0) \leftrightarrow \mathrm{H}_{2} \mathrm{O}\left(v_{1} ; v_{2} 1 ; v_{3}\right)+\mathrm{O}_{2}(1)$ & $\mathrm{V}-\mathrm{V}$ & $\mathrm{N} v_{2} \times 1.68 \times 10^{12}$ & Bass and Shields (1974) \\
\hline 2 & $\mathrm{O}_{2}(1)+\mathrm{O}\left({ }^{3} \mathrm{P}\right) \leftrightarrow \mathrm{O}_{2}(0)+\mathrm{O}\left({ }^{3} \mathrm{P}\right)$ & $\mathrm{V}-\mathrm{T}$ & $1.3 \times 10^{12} \times(T / 300.0)^{1 / 2}$ & Breen et al. (1973) \\
\hline 3 & $\mathrm{O}_{2}(1)+\mathrm{CO}_{2}(000) \leftrightarrow \mathrm{O}_{2}(0)+\mathrm{CO}_{2}\left(0_{2} 0\right)$ & $\mathrm{V}-\mathrm{V}$ & $9.1 \times 10^{15} \times T^{1 / 2} \times \exp \left(-56.7 / T^{1 / 2}\right)$ & $\begin{array}{l}\text { Bass (1973) } \\
\text { López-Puertas et al. (1995) }\end{array}$ \\
\hline \multirow[t]{3}{*}{4} & $\mathrm{O}_{2}(1)$ pumping from $\mathrm{O}_{2} / \mathrm{O}_{3}$ photolysis products & $\mathrm{E}-\mathrm{V}$ & a) $\epsilon=4$ & $\begin{array}{l}\text { a) López-Puertas et } \\
\text { al. (1995) }\end{array}$ \\
\hline & & $\mathrm{V}-\mathrm{V}$ & b) full photochemical model & $\begin{array}{l}\text { b) Yankovsky and } \\
\text { Manuilova (2006) }\end{array}$ \\
\hline & & $\mathrm{V}-\mathrm{T}$ & $\begin{array}{l}\text { c) simplified photochemical model with } \\
\text { variable } \epsilon\end{array}$ & $\begin{array}{l}\text { c) Yankovsky and Babaev } \\
\text { (2009) }\end{array}$ \\
\hline 5 & $\mathrm{H}_{2} \mathrm{O}\left(v_{1} ; v_{2} ; v_{3}\right)+\mathrm{N}_{2}(0) \leftrightarrow \mathrm{H}_{2} \mathrm{O}\left(v_{1} ; v_{2} 1 ; v_{3}\right)+\mathrm{N}_{2}(1)$ & $\mathrm{V}-\mathrm{V}$ & $\mathrm{N} v_{2} \times 3.39 \times 10^{15} \times T \times \exp \left(-27.0 / T^{1 / 3}\right)$ & $\begin{array}{l}\text { Whitson and McNeal } \\
\text { (1977) }\end{array}$ \\
\hline 6 & $\mathrm{O}\left({ }^{1} \mathrm{D}\right)+\mathrm{N}_{2}(0) \leftrightarrow \mathrm{O}\left({ }^{3} \mathrm{P}\right)+\mathrm{N}_{2}(1)$ & $\mathrm{E}-\mathrm{V}$ & $3.06 \times 10^{11} \times \exp (110.0 / T)$ & $\begin{array}{l}\text { Zahr et al. (1975) } \\
\text { Harris and Adams (1983) } \\
\text { Tachikawa et al. (1995) }\end{array}$ \\
\hline 7 & $\mathrm{H}_{2} \mathrm{O}\left(v_{1} ; v_{2} ; v_{3}\right)+\mathrm{M} \leftrightarrow \mathrm{H}_{2} \mathrm{O}\left(v_{1} ; v_{2} 1 ; v_{3}\right)+\mathrm{M}$ & $\mathrm{V}-\mathrm{T}$ & $\mathrm{N} v_{2} \times 4.1 \times 10^{14} \times(T / 300.0)^{1 / 2}$ & Bass et al. (1976) \\
\hline 8 & $\mathrm{H}_{2} \mathrm{O}\left(v_{1} ; v_{2} ; v_{3}\right)+\mathrm{O}\left({ }^{3} \mathrm{P}\right) \leftrightarrow \mathrm{H}_{2} \mathrm{O}\left(v_{1} ; v_{2} 1 ; v_{3}\right)+\mathrm{O}\left({ }^{3} \mathrm{P}\right)$ & $\mathrm{V}-\mathrm{T}$ & $\mathrm{N} \nu_{2} \times 1.0 \times 10^{12} \times(T / 300.0)^{1 / 2}$ & López-Puertas et al. (1995) \\
\hline 9 & $\mathrm{H}_{2} \mathrm{O}\left(v_{1} ; v_{2} ; v 3\right)+\mathrm{N}_{2} \leftrightarrow \mathrm{H}_{2} \mathrm{O}\left(v_{1}+1 ; v_{2} ; v_{3} 1\right)+\mathrm{N}_{2}$ & $\mathrm{~V}-\mathrm{T}$ & $1.2 \times 10^{11} \times T^{1 / 2}$ & López-Puertas et al. (1995) \\
\hline 10 & $\mathrm{H}_{2} \mathrm{O}\left(v_{1} ; v_{2} ; v_{3}\right)+\mathrm{O}_{2} \leftrightarrow \mathrm{H}_{2} \mathrm{O}\left(v_{1}+1 ; v_{2} ; v_{3} 1\right)+\mathrm{O}_{2}$ & $\mathrm{~V}-\mathrm{T}$ & $1.1 \times 10^{11} \times T^{1 / 2}$ & López-Puertas et al. (1995) \\
\hline 11 & $\mathrm{H}_{2} \mathrm{O}\left(v_{1} ; v_{2} ; v_{3}\right)+\mathrm{N}_{2} \leftrightarrow \mathrm{H}_{2} \mathrm{O}\left(v_{1} 1 ; v_{2}+2 ; v_{3}\right)+\mathrm{N}_{2}$ & & & \\
\hline 12 & $\mathrm{H}_{2} \mathrm{O}\left(v_{1} ; v_{2} ; v_{3}\right)+\mathrm{N}_{2} \leftrightarrow \mathrm{H}_{2} \mathrm{O}\left(v_{1} ; v_{2}+2 ; v_{3} 1\right)+\mathrm{N}_{2}$ & $\mathrm{~V}-\mathrm{T}$ & $4.6 \times 10^{13} \times(T / 300.0)^{1 / 2}$ & Finzi et al. (1977) \\
\hline 13 & $\mathrm{H}_{2} \mathrm{O}\left(v_{1} ; v_{2} ; v 3\right)+\mathrm{O}_{2} \leftrightarrow \mathrm{H}_{2} \mathrm{O}\left(v_{1} 1 ; v_{2}+2 ; v_{3}\right)+\mathrm{O}_{2}$ & & & \\
\hline 14 & $\mathrm{H}_{2} \mathrm{O}\left(v_{1} ; v_{2} ; v_{3}\right)+\mathrm{O}_{2} \leftrightarrow \mathrm{H}_{2} \mathrm{O}\left(v_{1} ; v_{2}+2 ; v_{3} 1\right)+\mathrm{O}_{2}$ & $\mathrm{~V}-\mathrm{T}$ & $3.3 \times 10^{13} \times(T / 300.0)^{1 / 2}$ & Finzi et al. (1977) \\
\hline 15 & $\mathrm{H}_{2} \mathrm{O}\left(v_{1} ; v_{2} ; v_{3}\right)+\mathrm{O}\left({ }^{3} \mathrm{P}\right) \leftrightarrow \mathrm{H}_{2} \mathrm{O}\left(v_{1} 1 ; v_{2}+2 ; v_{3}\right)+\mathrm{O}\left({ }^{3} \mathrm{P}\right)$ & & & \\
\hline 16 & $\mathrm{H}_{2} \mathrm{O}\left(v_{1} ; v_{2} ; v_{3}\right)+\mathrm{O}\left({ }^{3} \mathrm{P}\right) \leftrightarrow \mathrm{H}_{2} \mathrm{O}\left(v_{1} ; v 2+2 ; v_{3} 1\right)+\mathrm{O}\left({ }^{3} \mathrm{P}\right)$ & $\mathrm{V}-\mathrm{T}$ & $3.0 \times 10^{12} \times(T / 300.0)^{1 / 2}$ & Zittel and Masturzo (1989) \\
\hline
\end{tabular}

In this table $T$ is temperature in $\mathrm{K}$ and $\mathrm{N} v_{2}$ is the number of $v_{2}$-quanta.

(López-Puertas and Taylor, 2001). Besides exchanging energy with $\mathrm{O}_{2}(v)$ levels, the $\mathrm{H}_{2} \mathrm{O}\left(v_{2}\right)$ levels interact with $\mathrm{N}_{2}$ levels pumped through collisions with the electronically excited oxygen atoms $\mathrm{O}\left({ }^{1} \mathrm{D}\right)$ (Zahr et al., 1975; Harris and Adams, 1983; Tachikawa et al., 1995; Edwards et al., 1996).

The non-LTE effects in populations of $\mathrm{H}_{2} \mathrm{O}$ vibrational levels for the daytime conditions in a typical atmospheric scenario are shown in Fig. 2a. The non-LTE calculation for the case study in this plot was performed with the help of the research code ALI-ARMS (see Sect. 4 below) for mid-latitude conditions measured by the SABER instrument (June 23,2002 , lat $=39.6^{\circ} \mathrm{N}$, lon $=256.2^{\circ} \mathrm{E}$, solar zenith angle $\theta_{z}=79.58^{\circ}$ ). The $\mathrm{H}_{2} \mathrm{O}$ VMR profile was taken from the output of the LIMA (Leibniz-Institute Middle Atmosphere) model (Sonnemann et al., 2005; Berger, 2008) for the corresponding mid-latitude conditions. The profiles of other atmospheric gases required for the calculations $\left(\mathrm{N}_{2}, \mathrm{O}_{2}, \mathrm{CO}_{2}\right.$, $\mathrm{O}$, and $\mathrm{O}^{1} \mathrm{D}$ ) were taken from the corresponding SABER atmospheric model. The kinetic temperature profile and all VMR profiles were smoothed with a $4 \mathrm{~km}$ vertical window for demonstration purposes. The populations of the levels in Fig. 2a are represented by vibrational temperatures $T_{\mathrm{vib}}$ that describe the excitation degree of the level $l$ against the ground level 0: $n_{l} / n_{0}=g_{l} / g_{0} \exp \left[-\left(E_{l}-E_{0}\right) / k / T_{\text {vib }}\right]$, where $E_{l}$ is the energy of the level $l, E_{0}$ is the energy of the ground

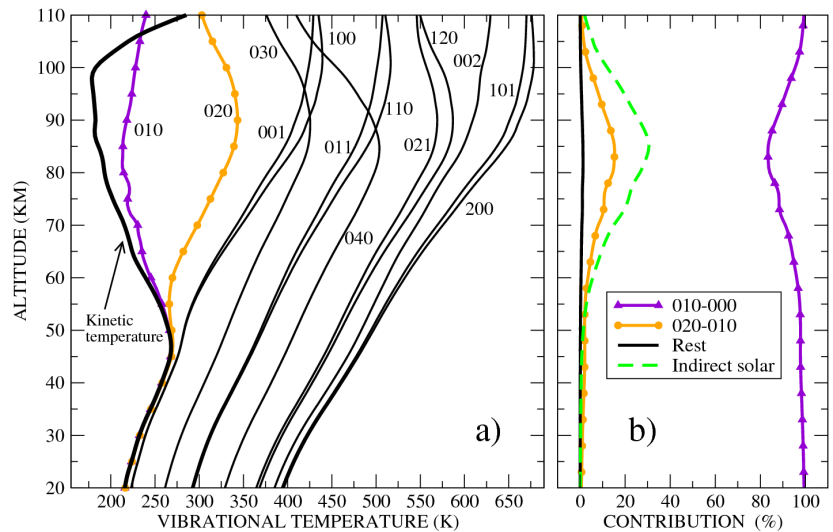

Fig. 2. Non-LTE effects in $\mathrm{H}_{2} \mathrm{O}$ vibrational levels. Simulation for mid-latitude conditions (23 June 2002 , lat $=39.6^{\circ} \mathrm{N}$, lon $=256.2^{\circ} \mathrm{E}$, $\theta_{z}=79.58^{\circ}$ ): (a) vibrational temperatures of $\mathrm{H}_{2} \mathrm{O}$ levels; (b) contributions of different radiative transitions to $6.6 \mu \mathrm{m}$ SABER channel. "Rest" is for contribution from optical transitions other than 020010 and 010-000 involved in the model in Fig. 1.

level, $k$ is Boltzmann's constant, and $g_{0}, g_{l}$ and $n_{0}, n_{l}$ are the degeneracies and populations of the ground and $l$-th levels, respectively. If the level is in LTE, then $T_{\mathrm{vib}}=T_{\mathrm{kin}}$. If 
$T_{\text {vib }}>T_{\text {kin }}$ then the net pumping of the level is larger than that under LTE conditions. Similarly, if $T_{\mathrm{vib}}<T_{\text {kin }}$, the level is populated less efficiently and/or depopulated faster than at LTE.

The curves in Fig. 2a are marked in accordance with the level nomenclature from Fig. 1 . One can see that the $T_{\text {vib }}$ of different vibrational levels demonstrate different behavior. The populations of 010 and 020 levels depart from LTE above $\sim 55 \mathrm{~km}$ altitude while levels such as 030, 100, 011, $110,040,021,120,002,101$, and 200 show the effects of strong solar pumping down to the troposphere. The populations of the 001 and 100 levels are close to LTE below $\sim 45 \mathrm{~km}$ altitude though LTE is disturbed both by weak absorption of solar radiance in line wings and by pumping from the upper levels. The contributions of various bands to the simulated SABER $6.6 \mu \mathrm{m}$ radiance are shown in Fig. $2 \mathrm{~b}$. The figure demonstrates that the fundamental $\nu_{2}$ band (010-000 transition) dominates the $6.6 \mu \mathrm{m}$ radiance at all altitudes with $\sim 15-20 \%$ contribution of the first hot band transition $(020-010)$ in the altitude range of $60-100 \mathrm{~km}$. Though there is no direct contribution of the transitions from the upper vibrational levels, these levels must be included in the daytime calculations since they pump the 010 and 020 levels through a series of $\mathrm{V}-\mathrm{V}$ and $\mathrm{V}-\mathrm{T}$ exchanges as well as through radiative transitions. The indirect contribution of the upper levels to the daytime $6.6 \mu \mathrm{m}$ radiance measured by SABER was calculated and put on Fig. $2 \mathrm{~b}$ to be compared with the contributions of the 010-000 and 020-010 transitions (see the dashed line in Fig. 2b). One can see that approximately $30 \%$ of the daytime signal in the SABER water vapor channel near $85 \mathrm{~km}$ is due to pumping the 020 and 010 levels from the upper levels.

\section{ALI-ARMS research code}

Most of the calculations performed in this work were made using the ALI-ARMS computer code (see Kutepov et al., 1998; Gusev and Kutepov, 2003; and references therein) that solves the multi-level problem using the Accelerated Lambda Iteration (ALI) technique developed for calculating non-LTE populations of atomic and ionic levels in stellar atmospheres (Rybicki and Hummer, 1991). The code iteratively solves a set of statistical equilibrium equations and the radiative transfer equations. The algorithm efficiency is ensured by the ALI technique, which avoids the expensive radiative transfer calculations for the photons trapped in the optically thick cores of spectral lines. The ALI-ARMS model was successfully applied by Kaufmann et al. $(2002,2003)$ and Gusev et al. (2006) to the non-LTE diagnostics of spectral Earth's limb observations from the CRISTA instrument (Offermann et al., 1999; Grossmann et al., 2002). Kutepov et al. (2006) used this model to validate the SOPC used for temperature retrievals from the $15 \mu \mathrm{m} \mathrm{CO}_{2}$ emissions measured by SABER. The retrieval method implemented in the
ALI-ARMS code is similar to that used in the SOPC, which is based on an iterative onion-peel technique using the relaxation method described in Gordley and Russell (1981). The process starts with the initial guess on a water vapor profile combined with a fixed atmospheric model (pressure, temperature, and VMRs of atmospheric gases retrieved from a corresponding SABER measurement). The non-LTE populations are calculated and used for monochromatic limb radiances calculations for each limb-path that are convolved with the instrumental function for SABER water vapor channel. The resulting simulated radiance $I$ is compared to the measured radiance at each tangent height, and the water vapor VMR is iterated using the following relaxation scheme: $\xi^{i+1}=\xi^{i}+\left(I_{\text {meas }}-I^{i}\right) /(\partial I / \partial \xi)$, where $\xi^{i+1}$ and $\xi^{i}$ are the water vapor VMRs at the $i+1$-th and $i$-th iterations, respectively, $I_{\text {meas }}$ is the limb radiance measured by SABER, $I^{i}$ is the simulated limb radiance at the $i$-th iteration, and $(\partial I / \partial \xi)$ is the numerically calculated derivative of the radiance produced by the forward model with respect to $\xi$. After all limbpaths are converged, a new $\mathrm{H}_{2} \mathrm{O}$ VMR profile is produced, and new non-LTE populations of $\mathrm{H}_{2} \mathrm{O}$ molecular levels are calculated, the radiance is simulated again. The iterations are repeated until the differences between the simulated and measured radiances become equal to the radiance noise in the channel.

Figure 3 shows the self-consistency check of the retrieval procedure performed for the model atmosphere discussed in Sect. 3.1. First, the non-LTE task was solved for the reference $\mathrm{H}_{2} \mathrm{O}$ profile, and the limb radiance was calculated using the non-LTE populations of the $\mathrm{H}_{2} \mathrm{O}$ levels, observation geometry, and the SABER instrumental function. Second, the resulting radiance profile was used as the "measured" profile $\left(I_{\text {meas }}\right)$. Two tests were then conducted. The initial guess $\mathrm{H}_{2} \mathrm{O}$ VMR profile was set equal to $1.0 \times 10^{-6}$ (case I) and $1.0 \times 10^{-5}$ (case II) in the $50-100 \mathrm{~km}$ altitude range. Below and above this range the original values of the $\mathrm{H}_{2} \mathrm{O}$ profile were used. The retrieval procedure was run for both cases. Figure 3a shows that the retrieved $\mathrm{H}_{2} \mathrm{O}$ profile rapidly converges to the reference profile in the course of iterations and that the result does not depend on the initial profile. Figure $3 b$ demonstrates the difference between the simulated and reference radiances at each iteration. One can see that the converged radiance profile reproduces the reference profile at all points in the $50-100 \mathrm{~km}$ altitude range.

The described approach was tested on a number of atmospheric profiles typical for different seasons and locations. The retrieval algorithm demonstrated the same convergence stability and independence of the resulting profile on the initial guess. Potential issues with the retrieval of this kind are related to the cases where the contribution of a given tangent point to the limb-path-integrated radiance becomes small in comparison with the integrated contribution of the atmosphere lying above. This can happen if the absolute number of emitting molecules rapidly decreases with altitude and the upper part of the atmosphere "blankets" the tangent 

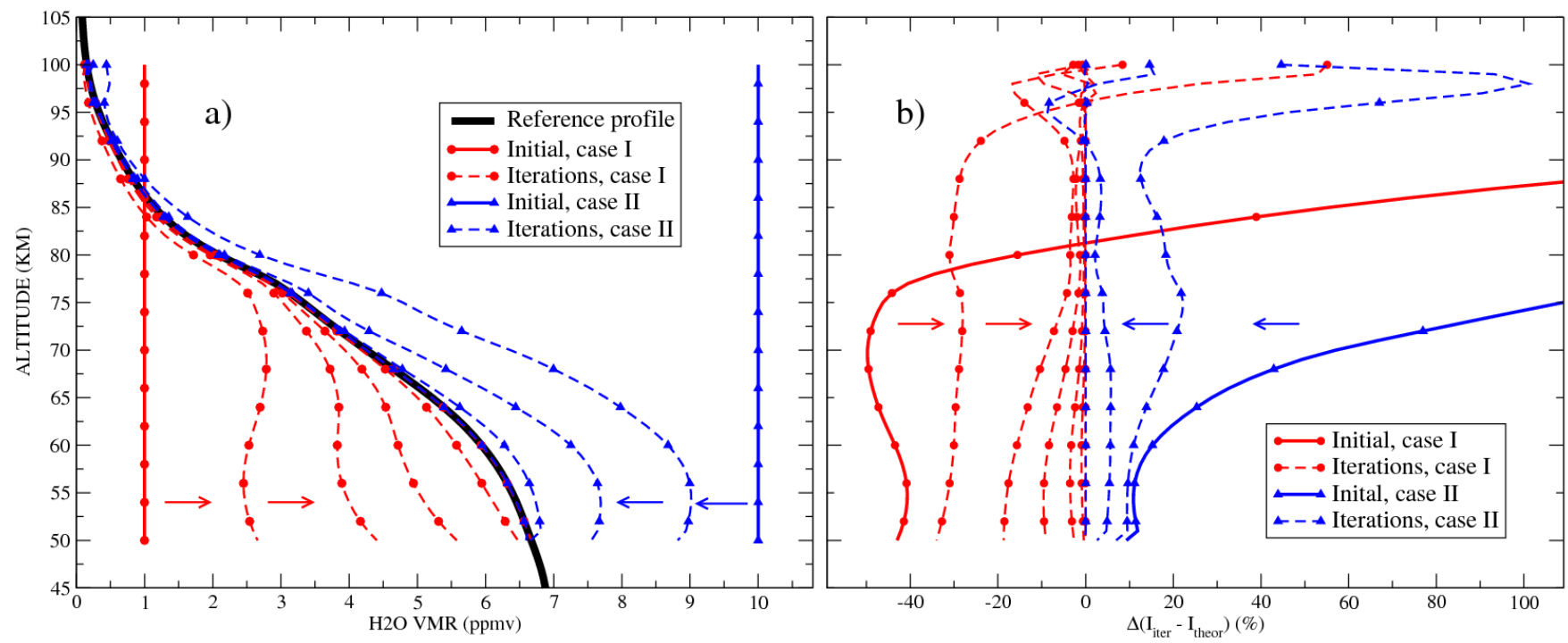

Fig. 3. Self-consistent retrievals of $\mathrm{H}_{2} \mathrm{O}$ density in the $50-100 \mathrm{~km}$ altitude range: (a) iterations starting with two different initial guess $\mathrm{H}_{2} \mathrm{O}$ VMR profiles: $1.0 \times 10^{-6}$ (case I) and $1.0 \times 10^{-5}$ (case II); (b) percent difference between the reference and calculated radiance profiles in the course of iterations for cases I and II.

point. This scenario is realized if either the $\mathrm{H}_{2} \mathrm{O}$ VMR or vibrational levels pumping falls rapidly with altitude. Fortunately, the $\mathrm{H}_{2} \mathrm{O}$ VMR profiles in the Earth's atmosphere do not experience rapid falloffs when moving from top to bottom. To avoid the problem of insufficient levels pumping, we do not consider the nighttime cases or the measurements for which $\theta_{z} \geq 88.0^{\circ}$.

\section{Validating the non-LTE $\mathrm{H}_{2} \mathrm{O}$ model}

The accuracy of non-LTE modeling depends on the quality of the experimental and theoretical rate coefficients describing the populating and de-populating of the $\mathrm{H}_{2} \mathrm{O}$ vibrational states that are listed in Sect. 3. The largest source of error in the non-LTE area (above $65-70 \mathrm{~km}$ altitude) comes from the uncertainties in V-V and V-T rates (Manuilova et al., 2001). In this section we show the results of a sensitivity study performed for the $\mathrm{H}_{2} \mathrm{O}$ non-LTE model, describe the method that was applied to validating the set of rate coefficients used in the model, and suggest an update to some of these coefficients.

\subsection{Sensitivity study}

We examined the sensitivity of $\mathrm{H}_{2} \mathrm{O}\left(v_{2}\right)$, and especially the $\mathrm{H}_{2} \mathrm{O}(010)$, populations to variations of $\mathrm{V}-\mathrm{V}$ rates, $\mathrm{V}-\mathrm{T}$ rates, and effective quantum yield $\varepsilon$ for various atmospheric scenarios. We also estimated the effects of temperature uncertainties both in the LTE dominated and in the non-LTE dominated areas. Here we discuss the results for three test cases: tropical, mid-latitude winter, and polar summer (Figs. 4, 5, and 6, respectively). The atmo- spheric pressure-temperature profiles as well as profiles of other atmospheric gases, except $\mathrm{H}_{2} \mathrm{O}$, were taken from the current V1.07 SABER dataset (http://saber.gats-inc.com/). The parameters of the SABER scans used for sensitivity study are: lat $=1.23^{\circ} \mathrm{S}$, lon $=7.24^{\circ} \mathrm{E}, \theta_{z}=26.62^{\circ}$ for tropics; lat $=42.14^{\circ} \mathrm{S}$, lon $=11.2^{\circ} \mathrm{E}, \theta_{z}=64.12^{\circ}$ for mid-latitude winter; lat $=73.56^{\circ} \mathrm{N}$, lon $=22.59^{\circ} \mathrm{E}, \theta_{z}=55.96^{\circ}$ for polar summer. The scans were performed on days 198 and 199, 2002. The $\mathrm{H}_{2} \mathrm{O}$ profiles were modeled by LIMA (Berger, 2008) for the corresponding conditions. The left panels of Figs. 4-6 show the kinetic temperature $\left(T_{\text {kin }}\right)$ distributions for considered test cases as well as the vibrational temperatures of $\mathrm{H}_{2} \mathrm{O}(010), \mathrm{H}_{2} \mathrm{O}(020)$, and $\mathrm{O}_{2}(1)$ levels obtained by solving the non-LTE problem with the nominal set of rates from Table 1 . The mid-latitude winter and tropical temperature profiles are characterized by a moderate difference $(\sim 60-70 \mathrm{~K})$ between the stratopause and the mesopause. The vibrational temperature of the $\mathrm{H}_{2} \mathrm{O}(010)$ level for these cases deviates from the kinetic temperature in the MLT showing moderate non-LTE effects. On the other hand, the polar summer temperature profile (Fig. 6a) has stronger temperature gradients, and the stratopause-mesopause temperature difference is about twice as large as that obtained for mid-latitude winter and tropics, which is typical for this period (She and von Zahn, 1998). The vibrational temperatures shown in Fig. 6a illustrate that the non-LTE effects in the MLT are more pronounced during polar summer and, consequently, the solution of the non-LTE problem will be more sensitive to the rate coefficients. Common sense supported by results shown in Figs. 4a, 5a, and 6a suggests that one can expect the following behavior of the $\mathrm{H}_{2} \mathrm{O}(010)$ population with respect to various rate changes: increase of the $\mathrm{H}_{2} \mathrm{O}(010)$ quenching rate 

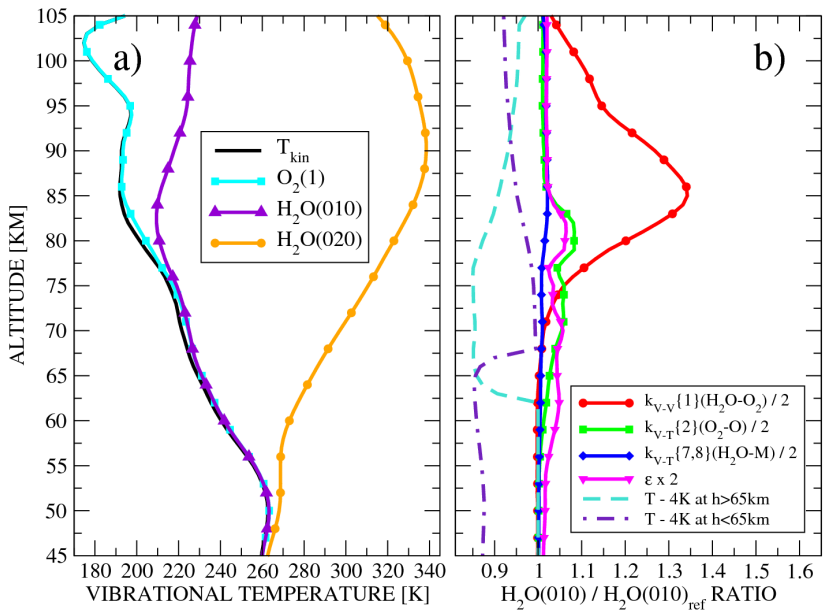

Fig. 4. Sensitivity study for the tropical case. (a) Temperature profile retrieved from SABER and vibrational temperatures of $\mathrm{H}_{2} \mathrm{O}(010), \mathrm{H}_{2} \mathrm{O}(020)$, and $\mathrm{O}_{2}(1)$ levels. (b) Sensitivity of the $\mathrm{H}_{2} \mathrm{O}(010)$ population to $k_{\mathrm{V}-\mathrm{V}}\{1\}\left(\mathrm{H}_{2} \mathrm{O}-\mathrm{O}_{2}\right), k_{\mathrm{V}-\mathrm{T}}\{2\}\left(O_{2}-\mathrm{O}\right)$, and $k_{\mathrm{V}-\mathrm{T}}\{7,8\}\left(\mathrm{H}_{2} \mathrm{O}-\mathrm{M}\right)$ rate coefficients and to local temperature variations.

must lead to a decrease in $\mathrm{H}_{2} \mathrm{O}(010)$ population at altitudes above $65-70 \mathrm{~km}$ for the tropical and mid-latitude modes. This is also true for polar summer up to $\sim 104 \mathrm{~km}$ altitude, where the $\mathrm{H}_{2} \mathrm{O}(010)$ vibrational temperature crosses the kinetic temperature profile and the effect reverses. Similarly, an increase of the $\mathrm{H}_{2} \mathrm{O}(010)-\mathrm{O}_{2}(1) \mathrm{V}-\mathrm{V}$ rate will lead to a more efficient de-population of the $\mathrm{H}_{2} \mathrm{O}(010)$ level and, as a result, to a $\mathrm{H}_{2} \mathrm{O}(010)$ population decrease in the $65-95 \mathrm{~km}$ altitude range, with the effect depending on the model. Using the same logic one can conclude that an increased $\mathrm{O}_{2}(1)$ quenching will result in a decreased $\mathrm{H}_{2} \mathrm{O}(010)$ population and, finally, that the enhanced $\mathrm{O}_{2}(1)$ pumping will cause the $\mathrm{H}_{2} \mathrm{O}(010)$ level population to increase.

Having this in mind we tested the sensitivity of the $\mathrm{H}_{2} \mathrm{O}(010)$ population to each of the following processes: $\mathrm{H}_{2} \mathrm{O}\left(v_{2}\right)-\mathrm{O}_{2}(1), \mathrm{H}_{2} \mathrm{O}\left(v_{2}\right)-\mathrm{N}_{2}(1)$, and $\mathrm{O}_{2}(1)-\mathrm{CO}_{2}(020) \mathrm{V}-\mathrm{V}$ exchanges, and $\mathrm{H}_{2} \mathrm{O}\left(v_{2}\right)-\mathrm{O}_{2}, \mathrm{H}_{2} \mathrm{O}\left(v_{2}\right)-\mathrm{N}_{2}, \mathrm{H}_{2} \mathrm{O}\left(v_{2}\right)-\mathrm{O}$, $\mathrm{O}_{2}(1)-\mathrm{O}_{2}, \mathrm{O}_{2}(1)-\mathrm{N}_{2}$, and $\mathrm{O}_{2}(1)-\mathrm{O} \mathrm{V}-\mathrm{T}$ quenching, and quantum yield $\varepsilon$ for the $\mathrm{O}_{2}(1)$ pumping. First, we performed a reference run for each atmospheric scenario with the rates from Table 1. Then, a series of test runs were made. For all test runs we fixed the rates in the non-LTE model except for one that was decreased to half its nominal value. We believe that for the purposes of our test, the rate decrease is more representative than its increase since the latter drives the level populations closer to LTE or to LTE in a group of levels while the former "decouples" the level from the other ones and/or from LTE. We also performed the runs with doubled quantum yield $\varepsilon=8$ to estimate the sensitivity of the $\mathrm{H}_{2} \mathrm{O}(010)$ population to $\mathrm{O}_{2}(1)$ level pumping. For each test run the resulting $\mathrm{H}_{2} \mathrm{O}(010)$ populations at different altitudes were compared to the reference ones. The re-

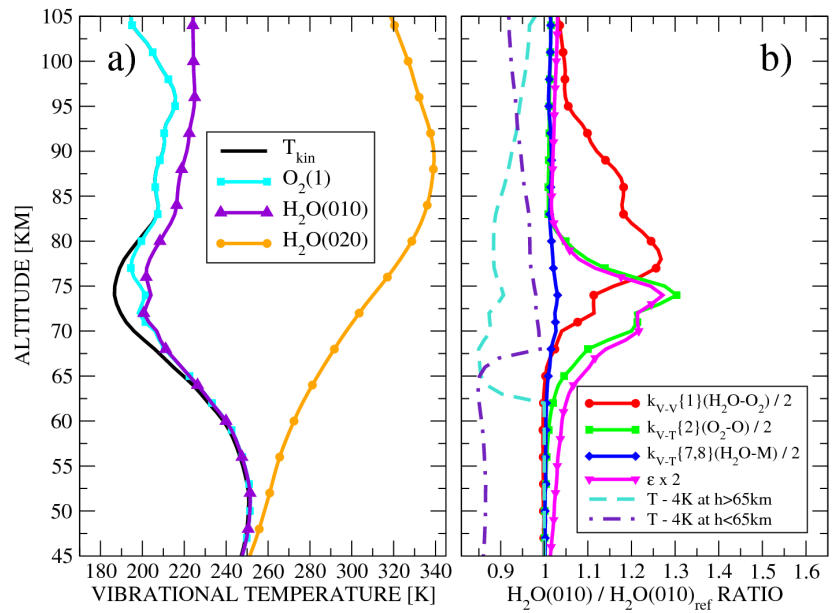

Fig. 5. Sensitivity study for the mid-latitude winter case. (a) Temperature profile retrieved from $\mathrm{SABER}$ and vibrational temperatures of $\mathrm{H}_{2} \mathrm{O}(010), \mathrm{H}_{2} \mathrm{O}(020)$, and $\mathrm{O}_{2}(1)$ levels. (b) Sensitivity of the $\mathrm{H}_{2} \mathrm{O}(010)$ population to $k_{V-V}\{1\}\left(\mathrm{H}_{2} \mathrm{O}-\mathrm{O}_{2}\right), k_{V-T}\{2\}\left(\mathrm{O}_{2}-\mathrm{O}\right)$, and $k_{\mathrm{V}-\mathrm{T}}\{7,8\}\left(\mathrm{H}_{2} \mathrm{O}-\mathrm{M}\right)$ rate coefficients and to local temperature variations.

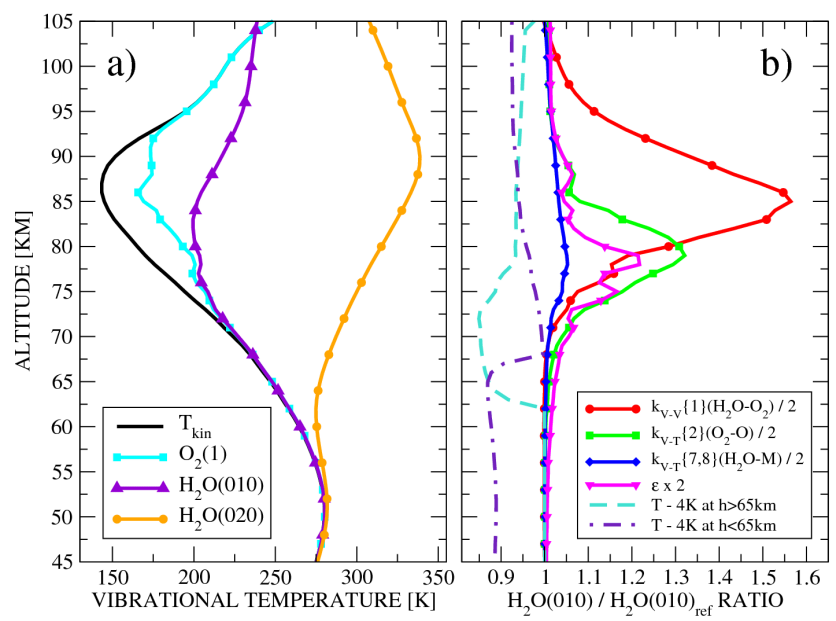

Fig. 6. Sensitivity study for the polar summer case. (a) Temperature profile retrieved from SABER and vibrational temperatures of $\mathrm{H}_{2} \mathrm{O}(010), \mathrm{H}_{2} \mathrm{O}(020)$, and $\mathrm{O}_{2}(1)$ levels. (b) Sensitivity of the $\mathrm{H}_{2} \mathrm{O}(010)$ population to $k_{\mathrm{V}-\mathrm{V}}\{1\}\left(\mathrm{H}_{2} \mathrm{O}-\mathrm{O}_{2}\right), k_{\mathrm{V}-\mathrm{T}}\{2\}\left(\mathrm{O}_{2}-\mathrm{O}\right)$, and $k_{\mathrm{V}-\mathrm{T}}\{7,8\}\left(\mathrm{H}_{2} \mathrm{O}-\mathrm{M}\right)$ rate coefficients and to local temperature variations.

sults of the study are shown on Figs. $4 b, 5 b$, and $6 b$ where the ratio of $\mathrm{H}_{2} \mathrm{O}(010)$ population obtained in the test case is compared with the reference one for a corresponding atmospheric scenarios and processes. For the sake of simplicity we show only the processes for which halving the corresponding reaction rate leads to more than a $3 \%$ change in the resulting $\mathrm{H}_{2} \mathrm{O}(010)$ population for either of the model atmospheres and for at least one altitude point. As anticipated, the polar summer case demonstrates the largest non-LTE effects 
in the set of three model atmospheres. For convenience we will refer to the processes from Table 1 using their type, number in the table, and the molecules/atoms involved in the reactions: $k_{V-V}\{1\}\left(\mathrm{H}_{2} \mathrm{O}-\mathrm{O}_{2}\right), k_{V-T}\{2\}\left(\mathrm{H}_{2} \mathrm{O}-\mathrm{M}\right)$, and so on. The highest sensitivity of the $\mathrm{H}_{2} \mathrm{O}(010)$ population and, therefore, of the $6.6 \mu \mathrm{m}$ radiance in the $65-100 \mathrm{~km}$ altitude range is to $k_{V-V}\{1\}\left(\mathrm{H}_{2} \mathrm{O}-\mathrm{O}_{2}\right)$ and $k_{V-T}\{2\}\left(\mathrm{O}_{2}-\mathrm{O}\right)$ rate coefficients though their importance varies for different atmospheric models: in the polar summer and tropical cases the $\mathrm{H}_{2} \mathrm{O}(010)$ population is more sensitive to $k_{V-V}\{1\}\left(\mathrm{H}_{2} \mathrm{O}-\mathrm{O}_{2}\right)$ while in the mid-latitude case the effects from $k_{V-V}\{1\}\left(\mathrm{H}_{2} \mathrm{O}-\mathrm{O}_{2}\right)$ and $k_{V-T}\{2\}\left(\mathrm{O}_{2}-\mathrm{O}\right)$ rates, and from doubling the quantum yield, are comparable. The combined effect of $k_{V-T}\{7\}\left(\mathrm{H}_{2} \mathrm{O}-\mathrm{N}_{2}, \mathrm{O}_{2}\right)$ and $k_{V-T}\{8\}\left(\mathrm{H}_{2} \mathrm{O}-\mathrm{O}\right)$ rates is less pronounced in all three scenarios reaching $5 \%$ only in the polar summer case.

Other parameters and factors that affect the $\mathrm{H}_{2} \mathrm{O}(010)$ population are (from most to least important): $\quad k_{V-V}\{3\}\left(\mathrm{O}_{2}-\mathrm{CO}_{2}\right), \quad k_{V-V}\{5\}\left(\mathrm{H}_{2} \mathrm{O}-\mathrm{N}_{2}\right)$, $k_{E-V}\{6\}\left(\mathrm{O}^{1} \mathrm{D}-\mathrm{N}_{2}\right)$, utilizing the simplified photochemical pumping of $\mathrm{O}_{2}(1)$ from $\mathrm{O}_{3}$ photolysis with constant profile of quantum yield $\varepsilon$, reducing the number of vibrational levels in the $\mathrm{H}_{2} \mathrm{O}$ model from 11 to 7 , and $k_{V-T}\{9\}\left(\mathrm{H}_{2} \mathrm{O}-\mathrm{N}_{2}\right)$ through $k_{V-T}\{16\}\left(\mathrm{H}_{2} \mathrm{O}-\mathrm{O}\right)$. The small effect of replacing the complicated scheme of $\mathrm{O}_{2} / \mathrm{O}_{3}$ photolysis product kinetics with the constant quantum yield profile needs an explanation. As follows from Manuilova et al. (2001) and Yankovsky and Babaev (2009) the simplified model does not provide an accurate estimate of $\mathrm{O}_{2}(1)$ pumping. However, utilizing it for the $\mathrm{H}_{2} \mathrm{O}$ non-LTE task appears to be reasonable. As the corresponding curves in Figs. $4 b, 5 b$, and $6 \mathrm{~b}$ show, the sensitivity to $\mathrm{O}_{2}(1)$ pumping peaks at $\sim 70-80 \mathrm{~km}$ altitude and becomes small at altitudes below $\sim 60 \mathrm{~km}$ and above $\sim 80 \mathrm{~km}$. Below $\sim 60 \mathrm{~km}$ the $\mathrm{O}_{2}(1)$ pumping is masked by LTE processes since any extra source is rapidly thermalized by frequent collisions. On the other hand, $\mathrm{O}_{2}(1)$ pumping above $80 \mathrm{~km}$ does not strongly affect the $\mathrm{H}_{2} \mathrm{O}(010)$ populations since the $\mathrm{V}-\mathrm{V}$ exchange decreases with decreasing pressure. Therefore, one can use a fixed quantum yield model for the purposes of $\mathrm{H}_{2} \mathrm{O}$ VMR retrieval because this model adequately describes the quantum yield in $60-80 \mathrm{~km}$ altitude range while avoiding the expensive $\mathrm{O}_{2} / \mathrm{O}_{3}$ photolysis product kinetics calculations. For the sake of accuracy, we suggest that $\mathrm{H}_{2} \mathrm{O}$ non-LTE models replace the constant quantum yield $\varepsilon=4$ with the average quantum yield profile estimated by Yankovsky and Babaev (2009). According to this work, $\varepsilon=8$ at $50 \mathrm{~km}$ altitude and falls with the altitude increase to $\varepsilon=6$ at $71 \mathrm{~km}, \varepsilon=4$ at $80 \mathrm{~km}, \varepsilon=1.5$ at $90 \mathrm{~km}$. It almost reaches zero at $100 \mathrm{~km}$ altitude. This profile was used in the current study.

\subsection{Sensitivity to local temperature}

Apart from being sensitive to rate coefficients of various processes, the $\mathrm{H}_{2} \mathrm{O}\left(v_{2}\right)$ populations and, consequently, ra- diances in the $6.6 \mu \mathrm{m}$ channel depend on local temperatures. Correspondingly, one has to estimate the possible effects of temperature uncertainty and bias prior to non-LTE model validation. This is of particular importance since recent estimates performed by Remsberg et al. (2008) show that the accuracy of the SABER temperature retrieval is about $\pm 2 \mathrm{~K}$ in the upper stratosphere and lower mesosphere. At the same time, SABER V1.07 temperatures (Remsberg et al., 2008; J.-H. Yee, private communications, 2009) show up to a $4 \mathrm{~K}$ negative bias in comparison with other measurements in the upper stratosphere and lower mesosphere. We performed the temperature sensitivity studies for all three atmospheric scenarios described above using the following approach. As one can see from Figs. 4a, 5a, and 6a, the approximate "LTE/nonLTE threshold" for all three atmospheric models is at $\sim 65 \mathrm{~km}$ altitude. Accordingly, two test runs for each atmosphere were made to estimate the local and non-local effects of temperature profile variation on water vapor retrieval. First, the temperature profile was modified in accordance with the formula:

$T_{\text {new }}(z)=T_{\text {old }}(z)-4.0 \times\left\{1-\exp \left[-\left(h(z)-h_{\text {threshold }}\right)\right]\right\}$,

where $T_{\text {new }}(z)$ is modified temperature value at the altitude point $z, T_{\text {old }}(z)$ is unperturbed temperature, $h(z)$ is altitude at point $z$ in $\mathrm{km}$, and $h_{\text {threshold }}$ is a threshold altitude in $\mathrm{km}$. For the first test profile the formula was applied for all altitudes $h(z)>h_{\text {threshold }}=62.0 \mathrm{~km}$. The second test profile was obtained by applying the correction defined by the formula: $T_{\text {new }}(z)=T_{\text {old }}(z)-4.0 \times\left\{1-\exp \left[-\left(h_{\text {threshold }}-h(z)\right)\right]\right\}$ for all altitudes $h(z)<h_{\text {threshold }}=68.0 \mathrm{~km}$. The results of the tests are shown on Figs. $4 b, 5 b$, and $6 b$, where the temperature sensitivity curves are in agreement with the non-LTE effects plotted on Figs. 4a, 5a, and 6a. For all cases considered here decreasing the temperature in the LTE area results in decreasing the $\mathrm{H}_{2} \mathrm{O}(010)$ population at all altitude levels where the correction was made. Moreover, the sensitivity of $\mathrm{H}_{2} \mathrm{O}(010)$ populations in the MLT to temperature changes in the stratosphere and lower mesosphere clearly shows that the absorption of radiance coming from below pumps the $\mathrm{H}_{2} \mathrm{O}(010)$ levels in the MLT. On the other hand, decreasing the temperature in non-LTE area has no effect on the $\mathrm{H}_{2} \mathrm{O}(010)$ population in the lower atmospheric layers though it still affects the $\mathrm{H}_{2} \mathrm{O}(010)$ populations locally. This effect decreases as the altitude increases and is less pronounced in the polar summer mesosphere in comparison with the tropical and mid-latitude cases. However, all three model cases demonstrate sensitivity of the $\mathrm{H}_{2} \mathrm{O}(010)$ population and, consequently, the water vapor retrieval, to kinetic temperature variations up to $\sim 80 \mathrm{~km}$ altitude. With this in mind we can start validating the $\mathrm{H}_{2} \mathrm{O}$ non-LTE model using a $\mathrm{H}_{2} \mathrm{O}$ VMR dataset that was retrieved from the measurements that are insensitive to nonLTE effects, namely, the ACE-FTS occultation experiment. 
Table 2. Various measurements of $k_{\mathrm{V}-\mathrm{V}}\{1\}\left(\mathrm{H}_{2} \mathrm{O}-\mathrm{O}_{2}\right)$ and $k_{\mathrm{V}-\mathrm{T}}\{2\}\left(\mathrm{O}_{2}-\mathrm{O}\right)$ rate coefficients.

\begin{tabular}{lll}
\hline Process & Rate coefficient, $\mathrm{cm}^{3} \mathrm{~s}^{-1}$ & References \\
\hline & $5.5 \times 10^{-13}$ & Huestis (2006), based on Diskin et al. (1996) \\
$1.0 \times 10^{-12}$ & Koukuli et al. (2006) \\
& $1.0-3.0 \times 10^{-12}$ & Zaragoza et al. (1998) \\
$k_{\mathrm{V}-\mathrm{V}\{1\}\left(\mathrm{H}_{2} \mathrm{O}-\mathrm{O}_{2}\right)}$ & $1.2 \times 10^{-12}$ & Zhou et al. (1999) \\
& $1.7 \times 10^{-12}$ & Bass and Shields (1974) \\
& $1.7-3.1 \times 10^{-12}$ & Edwards et al. (2000) \\
& $8.9 \times 10^{-12}$ & Bass et al. (1976) \\
& $1.3 \times 10^{-12}$ & Breen et al. (1973) \\
& $2.0 \times 10^{-12}$ & Ivanov et al. (2007) \\
& $2.6 \times 10^{-12}$ & Copeland (2008), Saran et al. (2008) \\
& $3.2 \times 10^{-12}$ & Kalogerakis et al. (2005) \\
& $3.4 \times 10^{-12}$ & Esposito and Capitelli (2007) \\
\hline
\end{tabular}

\subsection{ACE-FTS occultation measurements}

The Atmospheric Chemistry Experiment (ACE) on the SCISAT-1 platform, is a Canadian satellite for the remote sensing of the Earth's atmosphere that has been in operation since August 2003. The primary instrument on ACE is a Fourier-Transform Spectrometer (FTS) with $0.02 \mathrm{~cm}^{-1}$ spectral resolution. Working primarily in the solar occultation observation mode, it provides vertical profiles of temperature, pressure, and the VMRs for 18 atmospheric molecules in the $10-100 \mathrm{~km}$ altitude range at $4 \mathrm{~km}$ vertical resolution over the latitudes $85^{\circ} \mathrm{S}$ to $85^{\circ} \mathrm{N}$ (Bernath et al., 2005). Trace gas concentrations are retrieved from absorption features in microwindows, i.e. small $\left(\sim 0.3-1.0 \mathrm{~cm}^{-1}\right)$ portions of the spectrum that contain spectral features related to a molecule of interest with minimal spectral interference from other molecules (Boone et al., 2005; Boone et al., 2007). One advantage of using solar occultation for trace gases retrievals in the MLT is its independence from non-LTE issues since the instrument high spectral resolution allows tracking only the transitions from the ground state whose population can be considered to be equal to the total density of the specie. Recently, the comprehensive validation of the ACE-FTS water vapor profiles (Lambert et al., 2007; Carleer et al., 2008) has shown that the accuracy of $\mathrm{H}_{2} \mathrm{O}$ measurements is better than $5 \%$ in the $15-70 \mathrm{~km}$ altitude range and is better than $10 \%$ up to $82 \mathrm{~km}$ altitude. This makes the ACE-FTS measurements a suitable correlative dataset for comparison with SABER measurements.

\subsection{Rate coefficients validation}

As follows from Sect. 5.1, the $\mathrm{H}_{2} \mathrm{O}(010)$ population and, consequently, of retrieved $\mathrm{H}_{2} \mathrm{O}$ concentration or VMR, are most sensitive to the rates of the following processes: $\mathrm{H}_{2} \mathrm{O}\left(v_{2}\right)-\mathrm{O}_{2}(1) \mathrm{V}-\mathrm{V}$ exchange, $\mathrm{O}_{2}(1)-\mathrm{O} \mathrm{V}-\mathrm{T}$ quenching, and $\mathrm{H}_{2} \mathrm{O}\left(v_{2}\right)-\mathrm{N}_{2}, \mathrm{O}_{2}, \mathrm{O} \mathrm{V}-\mathrm{T}$ quenching with the corresponding rate coefficients $k_{V-V}\{1\}\left(\mathrm{H}_{2} \mathrm{O}-\mathrm{O}_{2}\right), k_{V-T}\{2\}\left(\mathrm{O}_{2}-\mathrm{O}\right)$, and $k_{V-T}\{7,8\}\left(\mathrm{H}_{2} \mathrm{O}-M\right)$. Here $M$ stands for $\mathrm{N}_{2}, \mathrm{O}_{2}$, and $\mathrm{O}$, while $\{7,8\}$ refers to the 7 -th and 8 -th rows in Table 1 , respectively. The measured and theoretically estimated values of $k_{V-V}\{1\}\left(\mathrm{H}_{2} \mathrm{O}-\mathrm{O}_{2}\right)$ and $k_{V-T}\{2\}\left(\mathrm{O}_{2}-\mathrm{O}\right)$ rate coefficients are given in Table 2. Apparently, the value of $k_{V-V}\{1\}\left(\mathrm{H}_{2} \mathrm{O}-\mathrm{O}_{2}\right)$ rate coefficient varies by more than an order of magnitude, and the largest value of $k_{V-T}\{2\}\left(\mathrm{O}_{2}-\mathrm{O}\right)$ is 2.5 times the smallest one. The estimates for the uncertainties of $k_{V-T}\{7,8\}\left(\mathrm{H}_{2} \mathrm{O}-M\right)$ from the work of Bass (1981) are of the same order as for the $k_{V-T}\{2\}\left(\mathrm{O}_{2}-\mathrm{O}\right)$. These uncertainties require searching for an optimal set of rates that will give the best agreement of the non-LTE measurement with reference climatologies and/or datasets.

We chose the following approach for finding this optimal set of rates. The SABER and ACE-FTS databases were searched to find the simultaneous common volume measurements in different seasons and at different latitudes. The altitude distribution of water vapor measured by ACE-FTS was taken as truth and used in a forward simulation of $6.6 \mu \mathrm{m}$ SABER radiance. All other atmospheric parameters (temperature, pressure, VMRs of other atmospheric components) were taken from the corresponding SABER record. The calculations were performed on a grid for each of the considered rates, and the resulting calculated radiances were compared with those measured by SABER in the non-LTE region. Then the chi-square $\left(\chi^{2}\right)$ space was searched for a minimum (Chapter 15 in Press et al., 2002) that provided the set of rate coefficients that, being applied to SABER measurements in $6.6 \mu \mathrm{m}$ channel, gives the best agreement between SABER and ACE-FTS. The coincidences have been selected around four seasonal turning points in both hemispheres in 2004 and 2005: vernal equinox, June solstice, boreal equinox, and December solstice. The total number of 


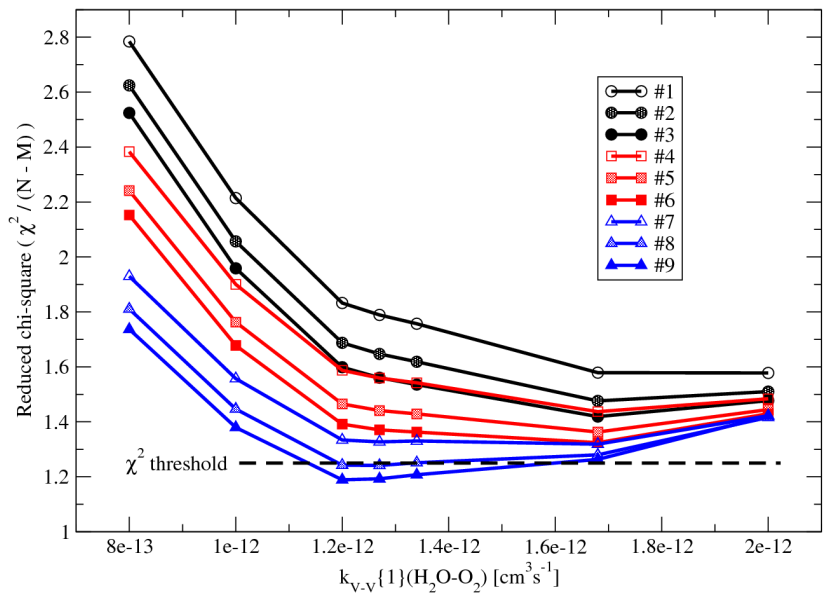

Fig. 7. Validation of the $\mathrm{H}_{2} \mathrm{O}$ non-LTE model using simultaneous common volume measurements of SABER and ACE-FTS. Each point represents a reduced $\chi^{2}$ value calculated for a certain combination of $k_{\mathrm{V}-\mathrm{V}}\{1\}\left(\mathrm{H}_{2} \mathrm{O}-\mathrm{O}_{2}\right), k_{\mathrm{V}-\mathrm{T}}\{2\}\left(\mathrm{O}_{2}-\mathrm{O}\right)$ and $k_{\mathrm{V}-\mathrm{T}}\{7,8\}\left(\mathrm{H}_{2} \mathrm{O}-\mathrm{M}\right)$ rates over 40 test atmospheres at the altitudes $60-85 \mathrm{~km}$. Abscissa refers to $k_{\mathrm{V}-\mathrm{V}}\{1\}\left(\mathrm{H}_{2} \mathrm{O}-\mathrm{O}_{2}\right)$ rate coefficient values, while the shape and shading of the symbols define the $k_{\mathrm{V}-\mathrm{T}}\{2\}\left(\mathrm{O}_{2}-\mathrm{O}\right)$ and $k_{\mathrm{V}-\mathrm{T}}\{7,8\}\left(\mathrm{H}_{2} \mathrm{O}-\mathrm{M}\right)$ rate coefficients. Circles: $k_{\mathrm{V}-\mathrm{T}}\{2\}\left(\mathrm{O}_{2}-\mathrm{O}\right)=1.8 \times 10^{-12} \mathrm{~cm}^{3} \mathrm{~s}^{-1}$; Squares: $\quad k_{\mathrm{V}-\mathrm{T}}\{2\}\left(\mathrm{O}_{2}-\mathrm{O}\right)=2.6 \times 10^{-12} \mathrm{~cm}^{3} \mathrm{~s}^{-1} ; \quad$ Triangles: $k_{\mathrm{V}-\mathrm{T}}\{2\}\left(\mathrm{O}_{2}-\mathrm{O}\right)=3.3 \times 10^{-12} \mathrm{~cm}^{3} \mathrm{~s}^{-1} ; \quad$ No symbol filling: $k_{\mathrm{V}-\mathrm{T}}\{7,8\}\left(\mathrm{H}_{2} \mathrm{O}-\mathrm{M}\right) / 1.4$; Meshed symbol filling: nominal $k_{\mathrm{V}-\mathrm{T}}\{7,8\}\left(\mathrm{H}_{2} \mathrm{O}-\mathrm{M}\right)$ from Table 1; Solid symbol filling: $k_{V-T}\{7,8\}\left(\mathrm{H}_{2} \mathrm{O}-\mathrm{M}\right) \times 1.4$.

profiles used for this validation was 40 . The SABER data for each coincident ACE-FTS scan were selected using the "overlapping weight" value estimated from the empirical formula: $\gamma=\Delta t \times 4+\Delta \eta \times 5+\Delta \zeta \times 1+6 /\left(90-\theta_{z}\right)$, where $\Delta t$ is time difference between the scans in hours, $\Delta \eta$ is latitude difference in degrees, $\Delta \zeta$ is longitude difference in degrees, $\theta_{z}$ is solar zenith angle in degrees, and numbers $4,5,1$, and 6 are the empirically found coefficients. The scans for which at least one of the following conditions was true: $\Delta t>1 \mathrm{~h}$, $\Delta \eta>4^{\circ}, \Delta \zeta>20^{\circ}, \theta_{z}>89^{\circ}$ were excluded from the comparison. We also excluded the up-scan events to eliminate biases related to hysteresis effects in the SABER detector. For each of the selected scans the corresponding SABER data were extracted from the V1.07 data base. The water vapor VMR profile was substituted with the coincident ACE-FTS VMR profile. All vertical profiles were interpolated onto a $1 \mathrm{~km}$ altitude grid.

According to Figs. 4-6, the non-LTE area is sensitive to both the local temperature and the temperature variations in the stratosphere. Therefore, the temperature biases in the atmospheric models selected for the comparison can affect the non-LTE analysis. From this point of view knowing and removing existing biases in the SABER V1.07 data set is crucial. Remsberg et al. (2008) have compared the
SABER temperatures with temperatures measured by lidars, MIPAS, and HALOE instruments and found a $2 \mathrm{~K}$ negative bias in SABER temperatures in the stratopause. This bias increases with the altitude increase and reaches $-8 \mathrm{~K}$ at the mesopause level. Unfortunately, the uncertainties in these biases are comparable or even larger than the biases themselves, and this does not allow using the vertical profile of the bias shown in this work. On the other hand, the comparison of SABER temperatures with the results obtained by the COSMIC GPS radio occultation experiment (J.-H. Yee, private communications, 2009) gives maximum negative deviation of $5 \mathrm{~K}$ in the stratopause region that decreases both in up- and downward directions. We note that neither comparison separated the upward and downward SABER scans, the former subject to detector hysteresis effects in the stratopause and lower mesosphere. In this work we use the uniform temperature correction obtained from the comparison of downward SABER scans and ACE-FTS temperature measurements. The correction can be approximated with the formula $T_{\text {new }}(z)=T_{\text {old }}(z)+4.0 \times \exp \left\{-0.007 \times[59.0-h(z)]^{2}\right\}$, where $T_{\text {new }}(z)$ is an updated temperature value at an altitude $z$, $T_{\text {old }}(z)$ is the unchanged SABER V1.07 temperature profile, 4.0 is the maximal temperature shift in $\mathrm{K}, 0.007$ is a damping parameter, 59.0 is the altitude (in $\mathrm{km}$ ) corresponding to a maximal temperature shift, and $h(z)$ is the altitude. This correction overlaps within uncertainty limits with the corrections suggested by Remsberg et al. (2008) and J.-H. Yee (private communications, 2009) and at the same time using the bias we suggest here makes the validation with ACE-FTS self-consistent. Improvements of the SABER temperature retrieval are ongoing, and the next release of SABER data will contain updated temperature profiles that will advance the temperature-dependent retrievals of atmospheric constituents at altitudes below $\sim 70 \mathrm{~km}$. We also note here that there are current limitations in the accuracy of V1.07 radiances which are under evaluation and will be updated in future releases of SABER data.

There were 63 rate combinations compiled from 7 values for $k_{V-V}\{1\}\left(\mathrm{H}_{2} \mathrm{O}-\mathrm{O}_{2}\right)$ rate coefficient, 3 values for $k_{V-T}\{2\}\left(\mathrm{O}_{2}-\mathrm{O}\right)$, and 3 values for $k_{V-T}\{7,8\}\left(\mathrm{H}_{2} \mathrm{O}-M\right)$. Each of these 63 combinations was applied to 40 tested atmospheres. For each of $63 \times 40=2520$ cases the ALI-ARMS simulated radiance $I_{\text {calc }}$ was compared to the measured one, $I_{\text {meas }}$, and the radiance discrepancies were analyzed at altitudes $60 \mathrm{~km}<h(z)<85 \mathrm{~km}$. The lower altitude limit of $60 \mathrm{~km}$ was selected because the non-LTE effects are mostly important above this altitude. The upper altitude limit of $85 \mathrm{~km}$ was set because of the radiance noise level. The analysis results are shown in Fig. 7, where the chi-square values (Press et al., 2002) are plotted. The $\chi^{2}$ values were calculated using the formula $\chi^{2}=\Sigma_{i, j}\left\{\left[I_{\text {meas }}(i, j)-I_{\text {calc }}(i, j)\right] / \sigma_{i, j}\right\}^{2}$, where $I_{\text {meas }}(i, j)$ is $6.6 \mu \mathrm{m}$ radiance measured by SABER, $I_{\text {calc }}(i, j)$ is the radiance calculated with the SABER atmosphere and ACE-FTS $\mathrm{H}_{2} \mathrm{O}$ VMR profile for $i$-th atmospheric model at $j$-th altitude point, $\sigma_{i, j}$ is the signal comparison 
Table 3. Sources of $\mathrm{H}_{2} \mathrm{O}$ retrieval errors and the total error, per cent values.

\begin{tabular}{lrrrrrrrrr}
\hline Altitude $[\mathrm{km}]$ & 50.0 & 55.0 & 60.0 & 65.0 & 70.0 & 75.0 & 80.0 & 85.0 & 90.0 \\
\cline { 1 - 7 } Source of error & & & & & & & & & \\
\cline { 1 - 7 }$k_{\mathrm{V}-\mathrm{V}\{1\}\left(\mathrm{H}_{2} \mathrm{O}-\mathrm{O}_{2}\right)}$ & $<1.0$ & $<1.0$ & 1.0 & 1.4 & 2.6 & 4.8 & 11.9 & 19.6 & 13.0 \\
$k_{\mathrm{V}-\mathrm{T}}^{*}\{\}\left(\mathrm{O}_{2}-\mathrm{O}\right)$ & $<1.0$ & $<1.0$ & 1.1 & 1.4 & 5.4 & 6.6 & 7.0 & 1.4 & $<1.0$ \\
$k_{\mathrm{V}-\mathrm{T}}^{*}\{7,8\}\left(\mathrm{H}_{2} \mathrm{O}-\mathrm{M}\right)$ & $<1.0$ & $<1.0$ & $<1.0$ & 1.0 & 1.4 & 2.2 & 1.6 & 1.0 & $<1.0$ \\
$k_{\text {rest }}$ & $<1.0$ & $<1.0$ & 1.0 & 1.5 & 2.0 & 3.0 & 4.0 & 3.0 & 2.0 \\
Temperature uncertainty & 10.7 & 9.4 & 8.2 & 6.3 & 4.5 & 4.9 & 2.5 & 2.0 & $<1.0$ \\
$I_{\text {meas }}$ & 1.4 & 1.7 & 2.1 & 2.4 & 5.3 & 7.5 & 10.0 & 20.0 & 100.0 \\
$I_{\mathrm{HITRAN}}$ vs. 14 vibrational levels & $<1.0$ & $<1.0$ & $<1.0$ & $<1.0$ & $<1.0$ & $<1.0$ & $<1.0$ & $<1.0$ & $<1.0$ \\
$\mathrm{O}_{2} / \mathrm{O}_{3}$ photochemistry & $<1.0$ & 1.0 & 1.7 & 2.6 & 3.5 & 4.2 & 4.1 & 3.5 & 3.0 \\
Operational vs. research codes (implementation) & $<1.0$ & $<1.0$ & $<1.0$ & $<1.0$ & $<1.0$ & 1.3 & 2.2 & 2.4 & 1.0 \\
Total root-sum-square & 11.1 & 1.7 & 2.0 & 2.0 & 1.2 & 2.0 & 3.0 & 2.0 & 3.0 \\
& & 10.0 & 9.2 & 8.1 & 10.3 & 13.6 & 18.6 & 28.7 & $>100.0$ \\
\hline
\end{tabular}

uncertainty for the same point, and the sum is performed over all altitudes and atmospheric cases for a given set of the rate constants. The $\sigma_{i, j}$ values were estimated using SABER V1.07 radiance measurement uncertainty, error of ACE-FTS water vapor measurement, and atmospheric variability within $\Delta t, \Delta \eta$, and $\Delta \zeta$ limits. The obtained $\chi^{2}$ values were divided by $(\mathrm{N}-\mathrm{M})$ where $\mathrm{N}=1040=26 \times 40$ is the number of data points and $M=3$ is the number of parameters. The obtained measure is a "reduced $\chi^{2}$ statistic" that demonstrates the "goodness of fit" of the model. For a perfectly accurate model the variance of $\left[I_{\text {meas }}(i, j)-I_{\text {calc }}(i, j)\right]$ matches the $\sigma_{i, j}$ variance, and the reduced $\chi^{2}$ equals one. We note that the numerical interpretation of the $\chi^{2}$ values should be done with caution as the data used for $\chi^{2}$ calculation are not completely independent as required by the statistical theory. The radiances that belong to one vertical scan are coupled through the radiative transfer between vertical layers. Temperature sensitivity curves in Figs. 4-6 clearly show this coupling. Same effects are achieved by increasing the $\mathrm{H}_{2} \mathrm{O}$ VMR in the lower atmosphere. On the other hand, increasing the $\mathrm{H}_{2} \mathrm{O}$ VMR in the mesosphere will decrease the radiance escaping the stratospheric area. This reasoning does not change the general approach to a $\chi^{2}$ minimum search, although it does not allow a straightforward interpretation of its numerical value. Since $\chi^{2}$ depends on three parameters, $k_{V-V}\{1\}\left(\mathrm{H}_{2} \mathrm{O}-\mathrm{O}_{2}\right)$, $k_{V-T}\{2\}\left(\mathrm{O}_{2}-\mathrm{O}\right)$, and $k_{V-T}\{7,8\}\left(\mathrm{H}_{2} \mathrm{O}-M\right)$, Fig. 7 represents a four-dimensional picture. For simplicity we show the reduced $\chi^{2}$ dependencies as cross-sections where the abscissa corresponds to the $k_{V-V}\{1\}\left(\mathrm{H}_{2} \mathrm{O}-\mathrm{O}_{2}\right)$ parameter and 9 lines coded by colors and symbols represent 9 combinations of 3 $k_{V-T}\{2\}\left(\mathrm{O}_{2}-\mathrm{O}\right)$ values with 3 values of $k_{V-T}\{7,8\}\left(\mathrm{H}_{2} \mathrm{O}-M\right)$ rate coefficient. As follows from Fig. 7, the minimum of $\chi^{2}$ is reached when $k_{V-V}^{*}\{1\}\left(\mathrm{H}_{2} \mathrm{O}-\mathrm{O}_{2}\right)=1.2 \times 10^{-12} \mathrm{~cm}^{3} \mathrm{~s}^{-1}$, $k_{V-T}^{*}\{2\}\left(\mathrm{O}_{2}-\mathrm{O}\right)=3.3 \times 10^{-12} \mathrm{~cm}^{3} \mathrm{~s}^{-1}$, and the value of $k_{V-T}^{*}\{7,8\}\left(\mathrm{H}_{2} \mathrm{O}-\mathrm{M}\right)$ is 1.4 times enhanced in comparison with the $k_{V-T}\{7,8\}\left(\mathrm{H}_{2} \mathrm{O}-M\right)$ rates given in Table 1 . Here and below the asterisk symbols denote the rate coefficients that yield the best correlation between the SABER V1.07 and ACE-FTS $\mathrm{H}_{2} \mathrm{O}$ measurements. For the reasons described above we didn't use the $\left[\min \left\{\chi^{2}\right\}+1\right]$ value to define the confidence region for the rate coefficients. Instead, we set the $\chi^{2}$ threshold to 1.25 based on the quality of the retrieved $\mathrm{H}_{2} \mathrm{O}$ VMR profiles. Using this threshold we obtained the following values for the rate coefficients:

$$
\begin{aligned}
& k_{V-V}^{*}\{1\}\left(\mathrm{H}_{2} \mathrm{O}-\mathrm{O}_{2}\right)=(1.2+0.4 /-0.1) \times 10^{-12} \mathrm{~cm}^{3} \mathrm{~s}^{-1} \\
& k_{V-T}^{*}\{2\}\left(\mathrm{O}_{2}-\mathrm{O}\right)=(3.3 \pm 0.7) \times 10^{-12} \mathrm{~cm}^{3} \mathrm{~s}^{-1} \\
& k_{V-T}^{*}\{7,8\}\left(\mathrm{H}_{2} \mathrm{O}-M\right)=(1.4 \pm 0.4) \times k_{V-T}\{7,8\}\left(\mathrm{H}_{2} \mathrm{O}-M\right)
\end{aligned}
$$

\subsection{New rate coefficients}

Comparison of coefficients (1-3) with values given in Tables 1 and 2 shows that the $k_{V-V}^{*}\{1\}\left(\mathrm{H}_{2} \mathrm{O}-\mathrm{O}_{2}\right)$ rate coefficient retrieved from the combined SABER and ACE-FTS data is consistent with other recent measurements and estimates (Zhou et al., 1999; Koukuli et al., 2006; LópezPuertas, 2009). This result can be considered as independent since MIPAS measurements were not correlated with either SABER, or ACE. Our result for $k_{V-T}^{*}\{2\}\left(\mathrm{O}_{2}-\mathrm{O}\right)$ rate coefficient suggests that its value must be higher than previously assumed. This is consistent with the most recent measurements of Kalogerakis et al. (2005), Esposito and Capitelli (2007), Copeland (2008), and Saran et al. (2008). We also note that the enhanced values of $k_{V-T}^{*}\{7,8\}\left(\mathrm{H}_{2} \mathrm{O}-M\right)$ rate coefficients are within the uncertainty limits defined in the work of Bass (1981).

\subsection{Retrieval uncertainties}

The uncertainties described in the rate coefficient analysis were used for the error analysis in $\mathrm{H}_{2} \mathrm{O}$ VMR retrievals. Table 3 shows the uncertainties for a single profile related to 
various aspects of measurements and retrievals, as well as the total uncertainty. Individual values in Table 3 are averaged over the seasons and latitudes and are given in percent of the total $\mathrm{H}_{2} \mathrm{O}$ VMR value at given altitudes. Errors linked with three major rates uncertainties are presented in the corresponding " $k_{V-V}^{*}\{1\}\left(\mathrm{H}_{2} \mathrm{O}-\mathrm{O}_{2}\right)$ ", " $k_{V-T}^{*}\{2\}\left(\mathrm{O}_{2}-\mathrm{O}\right)$ ", and " $k_{V-T}^{*}\{7,8\}\left(\mathrm{H}_{2} \mathrm{O}-M\right)$ " rows. The " $k_{\text {rest }}$ " row shows the combined error due to uncertainties in other rates listed in Table 1. Errors related to SABER temperature uncertainties were estimated using the data of Remsberg et al. (2008) and J.-H. Yee (private communications, 2009). $I_{\text {meas }}$ in the table refers to errors linked to the noise in radiance measurements, while an "I $I_{\text {HITRAN" }}$ "row represents errors related to uncertainties in the HITRAN 2004 spectroscopic database.

Uncertainties introduced by model simplifications discussed in Sect. 3.2 and operational code implementations are shown next. The effects of reducing the number of vibrational levels from 14 to 7 are listed in the " 7 vs. 14 vibrational levels" row. The " $\mathrm{O}_{2} / \mathrm{O}_{3}$ photochemistry" row shows errors introduced by using a fixed quantum yield profile for $\mathrm{O}_{2}$ (1) pumping instead of a full photochemical model. The effects introduced by the SOPC operational code are shown in the "Operational vs research codes (implementation)" row. This error is estimated from the comparison of SABER operational code and ALI-ARMS and GRANADA research nonLTE codes that will be discussed in Sect. 7 and Fig. 9b.

As follows from Table 3, the largest uncertainty source below $\sim 65 \mathrm{~km}$ is the temperature uncertainty which is consistent with the sensitivity studies presented in Sect. 5. Above $\sim 65 \mathrm{~km}$ and below $\sim 80 \mathrm{~km}$ the rate coefficient uncertainties dominate the total error, and above $\sim 80 \mathrm{~km}$ the retrieval error is mostly defined by the noise in the signal. Guided by values in Table 3, we estimated the magnitude of individual retrieval errors in $\mathrm{H}_{2} \mathrm{O}$ VMR vertical profile as about $\pm 0.7 \mathrm{ppmv}$ around the stratopause and about \pm 0.3 ppmv near the mesopause. Knowing the contribution of various factors to the total uncertainty, we now discuss the actual SABER $\mathrm{H}_{2} \mathrm{O}$ VMR retrievals.

\section{$6 \mathrm{H}_{2} \mathrm{O}$ retrievals from SABER measurements}

\subsection{Input data}

Our first non-LTE $\mathrm{H}_{2} \mathrm{O}$ retrievals from SABER measurements were performed for 4 atmospheric scenarios selected in 2004 and 2007: vernal equinox, June solstice, boreal equinox, and December solstice. For each case only one orbit was selected thus providing an "instantaneous snapshot" of the atmosphere for which the earliest and the latest measurements are separated by less than an hour and latitudes vary by at least 90 degrees. As in Sect. 5.4, we chose only the downward scans to eliminate the hysteresis effects. The parameters of the selected scans are listed in Table 4. Particular days and orbits around seasonal turning points were selected such that the best latitudinal coverage for daytime SABER measurements was achieved. Vertical profiles of pressure, temperature, and VMRs of atmospheric gases were taken from current V1.07 SABER data (http://saber.gats-inc.com/). The V1.07 temperature profiles were corrected in accordance with the approach discussed in Sect. 5.4. All profiles were interpolated onto a $1 \mathrm{~km}$ vertical grid from $15 \mathrm{~km}$ through $135 \mathrm{~km}$ altitude. The SABER $\mathrm{H}_{2} \mathrm{O}$ retrievals were performed for altitudes 50.0-90.0 km. Coincident $\mathrm{H}_{2} \mathrm{O}$ VMR data interpolated from ACE-FTS measurements were used below and above this height region. The ALI-ARMS research code used for the retrievals was modified to include the updated rate coefficients (1-3). Other rate coefficients for the non-LTE modeling were taken from Table 1.

\section{2 $\mathrm{H}_{2} \mathrm{O}$ VMR retrievals}

The retrieved water vapor VMRs are shown in Fig. 8a-h. The upper and lower panels refer to the years 2004 and 2007, respectively. The panels from left to right represent 4 different seasons: vernal equinox, June solstice, boreal equinox, and December solstice. The latitudinal resolution on each panel is $\sim 6^{\circ}$. For clarity, retrieved altitudinal-latitudinal $\mathrm{H}_{2} \mathrm{O}$ VMR distributions were linearly interpolated onto a 1 degree latitudinal grid and smoothed in two dimensions $(3 \mathrm{~km}$ altitude by 2 degrees latitude window). The differences in the latitudinal coverage on the panels are due to changes in the daytime observation geometry for different seasons. The detailed analysis and comparison of SABER $\mathrm{H}_{2} \mathrm{O}$ VMR retrievals with other measurements and models is subject of a separate study and will not be given here.

\subsubsection{Absolute values}

First, we consider the minimum and maximum values of $\mathrm{H}_{2} \mathrm{O}$ VMR distributions in Fig. 8. The minimum values, below $0.5 \mathrm{ppmv}$, define the upper altitude limit for physically sound SABER $\mathrm{H}_{2} \mathrm{O}$ measurements, which appears to be in the $85-90 \mathrm{~km}$ range depending on latitude and season. The maximum values can be used to estimate the SABER $\mathrm{H}_{2} \mathrm{O}$ quality by comparing them to other measurements. As Fig. 8d-g and especially Fig. 8h show, the largest $\mathrm{SABER} \mathrm{H}_{2} \mathrm{O}$ VMR values exceed $8.0 \mathrm{ppmv}$ at altitudes around $60 \mathrm{~km}$. In general, these values seem to be somewhat larger than the data from other sources. Various measurements (Peter, 1998; Lambert et al., 2007; Nedoluha et al., 2007; Carleer et al., 2008) show that the $\mathrm{H}_{2} \mathrm{O}$ VMR values at $60 \mathrm{~km}$ usually do not exceed $7.5 \mathrm{ppmv}$. Occasional increases of $\mathrm{H}_{2} \mathrm{O}$ VMR up to 7.8 ppmv at $60 \mathrm{~km}$ near boreal equinox were reported by Nedoluha et al. (1996), Nedoluha et al. (1998), and Peter (1998), and were partially explained by an increase in tropospheric methane emissions. Although these discrepancies are within declared accuracies of the compared datasets, we believe that they will be reduced after the SABER pressure-temperature retrieval 

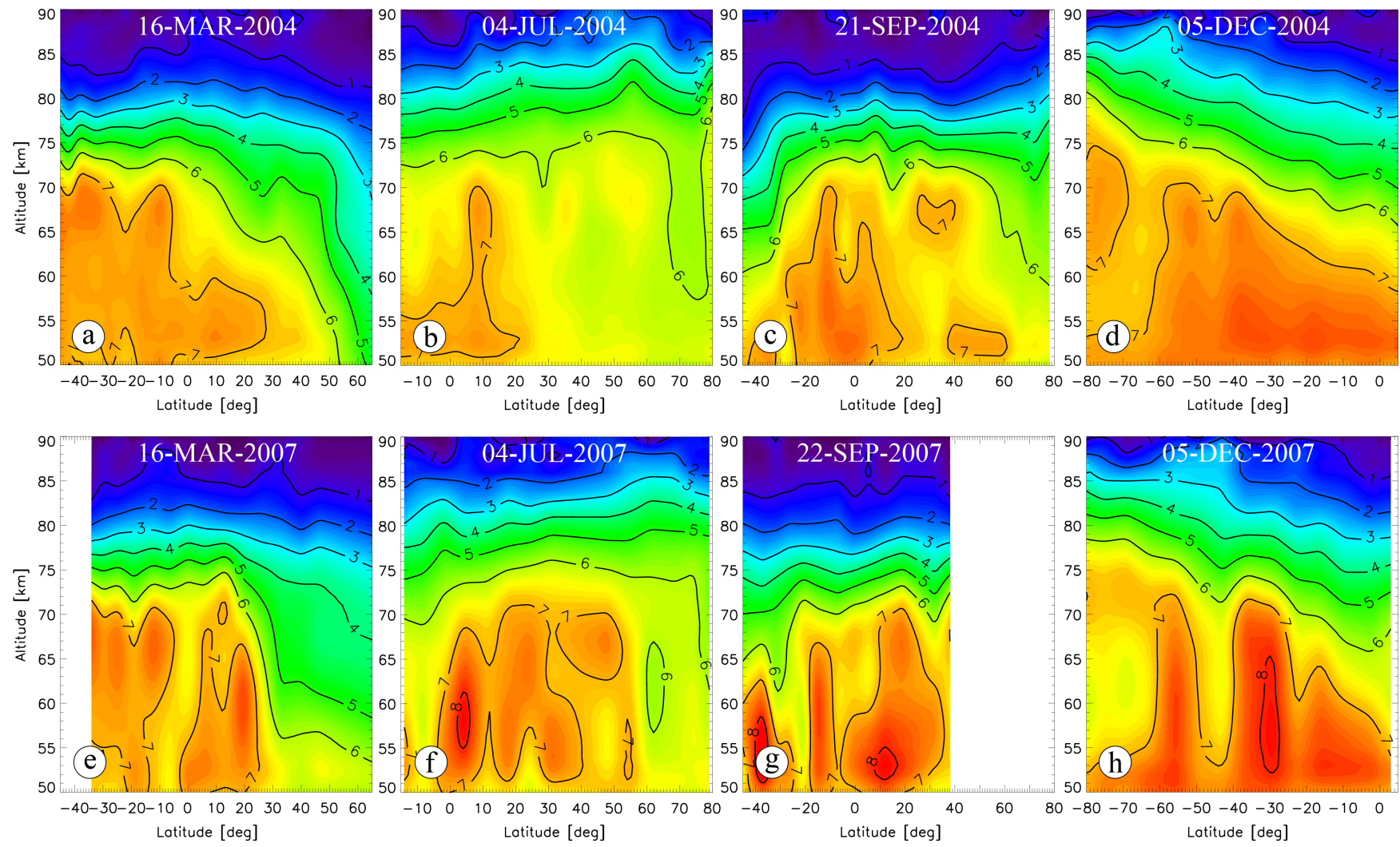

0.00 .51 .01 .52 .02 .53 .03 .54 .04 .55 .05 .56 .06 .57 .07 .58 .08 .5 H2O VMR [PPMV]

Fig. 8. Meridional distribution of $\mathrm{H}_{2} \mathrm{O}$ VMR retrieved from the SABER measurements. Upper panels: year 2004; lower panels: year 2007. Panels from left to right: vernal equinox, June solstice, north boreal equinox, and December solstice. Parameters of the scans: (a) Day of the year $=76$, orbit $=12295$, events 24-69; (b) Day of the year $=186$, orbit $=13928$, events 23-57; (c) Day of the year $=265$, orbit $=15102$, events 74-92, orbit $=15103$, events 00-20; (d) Day of the year $=340$, orbit $=16211$, events 39-71; (e) Day of the year $=75$, orbit $=28535$, events 24-54; (f) Day of the year $=185$, orbit $=30172$, events 24-53; $(\mathrm{g})$ Day of the year $=265$, orbit $=31350$, events 58-73, orbit $=31351$, events 00-12; (h) Day of the year $=339$, orbit $=32452$, events $45-71$.

Table 4. Parameters of SABER scans for $\mathrm{H}_{2} \mathrm{O}$ VMR retrievals.

\begin{tabular}{lccccc}
\hline Season & Year & Day & Orbit & Events & Figure \\
\hline Spring equinox & 2004 & 076 & 12295 & $24-69$ & $9 \mathrm{a}$ \\
Summer solstice in NH & 2004 & 186 & 13928 & $23-57$ & $9 \mathrm{~b}$ \\
Autumn equinox & 2004 & 265 & 15102 & $74-92$ & $9 \mathrm{c}$ \\
& & & 15103 & $00-20$ & \\
Summer solstice in SH & 2004 & 340 & 16211 & $39-71$ & $9 \mathrm{~d}$ \\
Spring equinox & 2007 & 075 & 28535 & $24-54$ & $9 \mathrm{e}$ \\
Summer solstice in NH & 2007 & 185 & 30172 & $24-53$ & $9 \mathrm{f}$ \\
Autumn equinox & 2007 & 265 & 31350 & $00-12$ & $9 \mathrm{~g}$ \\
& & & 31351 & $58-73$ & \\
Summer solstice in SH & 2007 & 339 & 32452 & $45-71$ & $9 \mathrm{~h}$
\end{tabular}

is re-analyzed, stimulated by the research of Remsberg et al. (2008), J.-H. Yee (private communications, 2009), and this work.
Table 5 shows the comparison of $\mathrm{H}_{2} \mathrm{O}$ VMR values obtained in this work with $\mathrm{H}_{2} \mathrm{O}$ VMR measured at Lauder $\left(45^{\circ} \mathrm{S}\right)$ and Mauna Loa $\left(19.5^{\circ} \mathrm{N}\right)$ by Nedoluha et al. (2007), and at ALOMAR $\left(69.2^{\circ} \mathrm{N}\right)$ by Sonnemann et al. (2009). The midlatitude SABER measurements were compared with MLS, HALOE, and WVMS (Nedoluha et al., 1997) data while the high latitude data were compared with $\mathrm{H}_{2} \mathrm{O}$ VMR profiles obtained with a microwave monitoring system (Hartogh et al., 1995; Sonnemann et al., 2009). Since vertical resolution of WVMS instrument and microwave spectrometer are much lower than that of SABER, for this comparison we convolved SABER profiles with the corresponding averaging kernels of these ground based instruments. As can be seen from Table 5, the SABER $\mathrm{H}_{2} \mathrm{O}$ VMR values at $50-80 \mathrm{~km}$ agree well, within the experimental uncertainties, with other measurements. We note that the uncertainties in Table 5 are larger than those shown in Table 3 due to convolution effects. In summary, our preliminary analysis of first 
Table 5. Comparing $\mathrm{H}_{2} \mathrm{O}$ VMR retrieved from SABER with other measurements.

\begin{tabular}{ccc}
\hline $\begin{array}{c}\text { Day \# / } \\
\text { Altitude, km / } \\
\text { Lat, deg }\end{array}$ & $\begin{array}{c}\mathrm{H}_{2} \mathrm{O} \text { VMR, ppmv } \\
\text { (Nedoluha et al., 2007) }\end{array}$ & $\begin{array}{c}\mathrm{H}_{2} \mathrm{O} \text { VMR, ppmv } \\
\text { (this work) }\end{array}$ \\
\hline 076/50.0/45.0 S & $7.0 \pm 0.2$ & $7.1 \pm 0.7$ \\
076/60.0/45.0 S & $7.7 \pm 0.3$ & $7.5 \pm 0.8$ \\
076/70.0/45.0 S & $5.9 \pm 0.2$ & $5.8 \pm 0.9$ \\
265/50.0/45.0 S & $6.7 \pm 0.3$ & $6.9 \pm 0.7$ \\
265/60.0/45.0 S & $6.2 \pm 0.6$ & $5.9 \pm 0.6$ \\
265/70.0/45.0 S & $4.1 \pm 0.7$ & $3.3 \pm 0.5$ \\
$340 / 50.0 / 45.0 \mathrm{~S}$ & $6.9 \pm 0.3$ & $7.2 \pm 0.7$ \\
$340 / 60.0 / 45.0 \mathrm{~S}$ & $7.1 \pm 0.2$ & $7.3 \pm 0.7$ \\
$340 / 70.0 / 45.0 \mathrm{~S}$ & $5.6 \pm 0.3$ & $6.0 \pm 0.9$ \\
$076 / 50.0 / 19.5 \mathrm{~N}$ & $6.4 \pm 0.2$ & $6.6 \pm 0.7$ \\
$076 / 60.0 / 19.5 \mathrm{~N}$ & $6.7 \pm 0.2$ & $6.7 \pm 0.7$ \\
$076 / 70.0 / 19.5 \mathrm{~N}$ & $4.9 \pm 0.3$ & $4.5 \pm 0.7$ \\
$186 / 50.0 / 19.5 \mathrm{~N}$ & $6.2 \pm 0.2$ & $6.5 \pm 0.7$ \\
$186 / 60.0 / 19.5 \mathrm{~N}$ & $7.0 \pm 0.3$ & $6.7 \pm 0.7$ \\
186/70.0/19.5 N & $5.7 \pm 0.4$ & $5.8 \pm 0.8$ \\
265/50.0/19.5 N & $6.7 \pm 0.2$ & $6.6 \pm 0.7$ \\
$265 / 60.0 / 19.5 \mathrm{~N}$ & $7.0 \pm 0.3$ & $6.9 \pm 0.7$ \\
265/70.0/19.5 N & $5.8 \pm 0.6$ & $5.8 \pm 0.8$ \\
\hline
\end{tabular}

Below this line: comparisons with Sonnemann et al. (2009)

\begin{tabular}{lll}
\hline $076 / 50.0 / 69.2 \mathrm{~N}$ & $4.5 \pm 0.3$ & $4.5 \pm 0.5$ \\
$076 / 60.0 / 69.2 \mathrm{~N}$ & $4.0 \pm 0.3$ & $3.7 \pm 0.4$ \\
$076 / 70.0 / 69.2 \mathrm{~N}$ & $2.2 \pm 0.2$ & $2.6 \pm 0.4$ \\
$076 / 80.0 / 69.2 \mathrm{~N}$ & $1.4 \pm 0.2$ & $1.6 \pm 0.4$ \\
$186 / 50.0 / 69.2 \mathrm{~N}$ & $7.0 \pm 0.5$ & $6.2 \pm 0.6$ \\
$186 / 60.0 / 69.2 \mathrm{~N}$ & $6.5 \pm 0.5$ & $6.0 \pm 0.6$ \\
$186 / 70.0 / 69.2 \mathrm{~N}$ & $6.7 \pm 0.6$ & $5.7 \pm 0.8$ \\
$186 / 80.0 / 69.2 \mathrm{~N}$ & $3.6 \pm 0.6$ & $4.5 \pm 1.0$ \\
$265 / 50.0 / 69.2 \mathrm{~N}$ & $7.5 \pm 0.5$ & $6.5 \pm 0.6$ \\
$265 / 60.0 / 69.2 \mathrm{~N}$ & $6.5 \pm 0.7$ & $6.0 \pm 0.6$ \\
$265 / 70.0 / 69.2 \mathrm{~N}$ & $5.0 \pm 0.6$ & $4.7 \pm 0.6$ \\
$265 / 80.0 / 69.2 \mathrm{~N}$ & $2.5 \pm 0.5$ & $3.0 \pm 0.6$ \\
\hline
\end{tabular}

SABER $\mathrm{H}_{2} \mathrm{O}$ VMR retrievals shows a good agreement with other measurements taking into account the accuracy of the compared data.

\subsubsection{Meridional structure}

The retrieved SABER water vapor distribution in Fig. 8a-h follows a known latitudinal pattern for seasons considered here. The $\mathrm{H}_{2} \mathrm{O}$ VMR decreases from the summer to the winter hemisphere is clearly seen in Fig. 8d, h and, to a lesser extent, in Fig. 8b, f. This is explained by changes in vertical wind during different seasons: the downward transport is increased in winter, but changes to the upward transport in summer (Garcia and Solomon, 1994; Körner and Sonnemann, 2001). As a result, in winter the air from above, where the $\mathrm{H}_{2} \mathrm{O}$ VMRs are small due to the mesospheric photochemical effects, moves down hence drying the atmosphere. The summertime mechanism works in the opposite direction giving rise to an increased $\mathrm{H}_{2} \mathrm{O}$ VMR in mesosphere. Another reason for the $\mathrm{H}_{2} \mathrm{O}$ VMR decrease from the summer to the winter hemisphere is the strong pressure decrease at high latitudes in the winter hemisphere that is linked with the lower temperatures below $\sim 70 \mathrm{~km}$ altitude.

The small-scale latitudinal structures that can be seen on nearly all panels of Fig. 8 can be explained by a strong vertical wind variability discussed by Körner and Sonnemann (2001). Their Fig. 5b shows that wind direction changes 6 times as the latitude varies from $60^{\circ} \mathrm{S}$ to $60^{\circ} \mathrm{N}$ leading to horizontal inhomogeneities in the $\mathrm{H}_{2} \mathrm{O}$ mixing ratio distributions. The differences between vernal equinoxes of 2004 and 2007 (Fig. 8a and e, respectively) can be explained by larger downward transport at high latitudes in 2007 that is seen as an abrupt change in $\mathrm{H}_{2} \mathrm{O}$ VMR decrease at $30^{\circ} \mathrm{N}$. The same trend is seen on Fig. $8 \mathrm{f}$ where well-defined horizontal structures reveal strong vertical wind variability, while low $\mathrm{H}_{2} \mathrm{O}$ VMR values at $10^{\circ} \mathrm{S}$ indicate the direction of vertical winds in this area. Larger peak values at heights around $60 \mathrm{~km}$ in 2007 can be explained both by larger vertical wind activity and photochemical effects. Generally, this maximum arises due to a competition of two photochemical processes: photodissociation of $\mathrm{H}_{2} \mathrm{O}$ in the mesosphere and methane oxidation. The variations of solar activity have their maximum effect on $\mathrm{H}_{2} \mathrm{O}$ VMR at heights above $65 \mathrm{~km}$ (Chandra et al., 1997). Enhanced tropospheric $\mathrm{CH}_{4}$ emissions give rise to increased water vapor in the stratosphere and lower mesosphere. One can explain the larger absolute values of $\mathrm{H}_{2} \mathrm{O}$ VMR in 2007 (Fig. 8e, g, and h) by a stronger vertical transport of methane from lower atmospheric layers. The comprehensive analysis of the latitudinal and seasonal variations that will be possible with the coming new release of SABER data will reveal more information about these atmospheric phenomena.

\section{From research to operational code}

The implementation of the non-LTE $\mathrm{H}_{2} \mathrm{O}$ model and retrieval algorithm in SOPC has been verified using two research nonLTE codes. The ALI-ARMS code was described above. The GRANADA code (López-Puertas et al., 1995; Funke et al., 2002) uses a general-purpose non-LTE algorithm that calculates vibrational and rotational non-LTE populations for relevant atmospheric IR emitters by iteratively solving the statistical equilibrium (SEE) and radiative transfer equations (RTE) with due consideration of radiative, collisional and chemical excitation processes. Internal radiation transfer is carried out with the KOPRA model (Stiller et al., 2000). The iteration scheme, i.e., the order of solutions of SEE and RTE, can be chosen by the user, allowing for Curtis matrix, lambda iteration, or mixed applications. Radiative transfer can be 

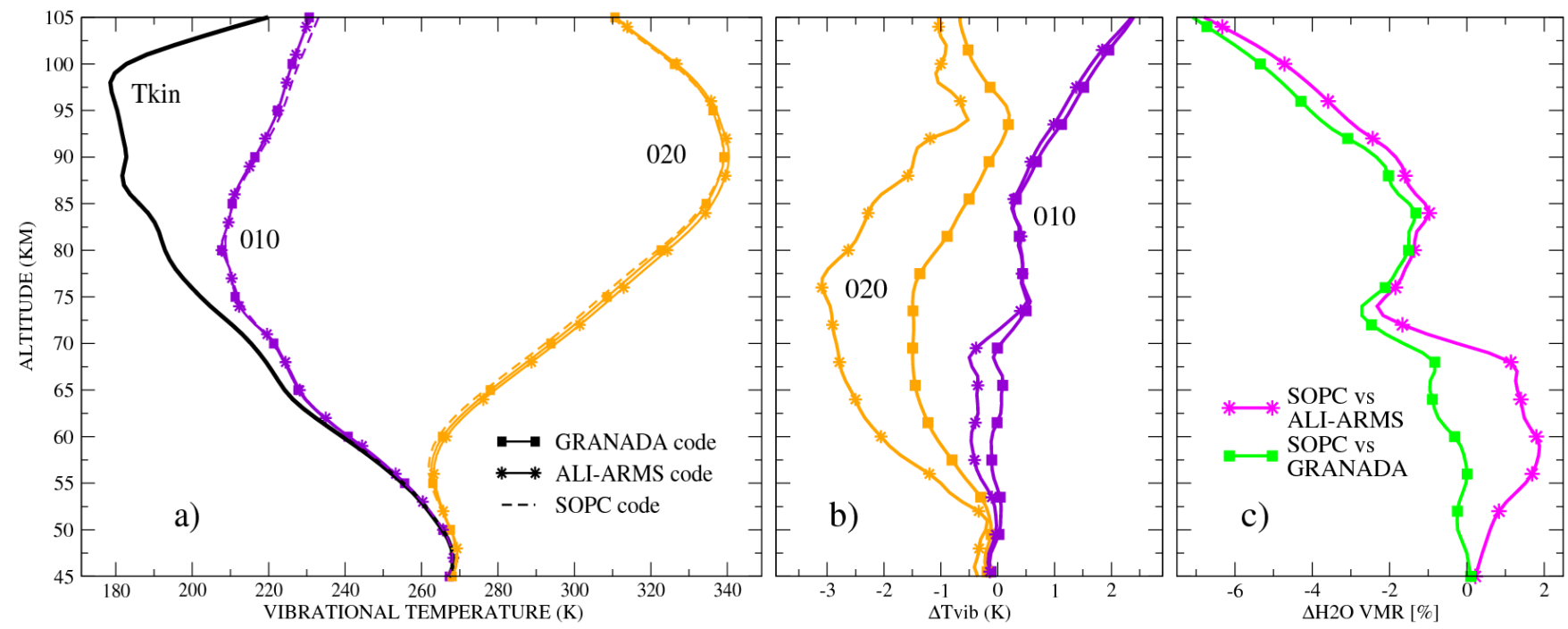

Fig. 9. Comparison of forward model for ALI-ARMS, GRANADA, and SOPC codes: (a) vibrational temperatures for 010 and 020 vibrational levels; (b) SOPC minus ALI-ARMS and SOPC minus GRANADA vibrational temperatures; (c) $\mathrm{H}_{2} \mathrm{O}$ VMR retrieval comparison: SOPC versus ALI-ARMS and GRANADA codes.

treated either line-by-line or by statistical band methods. For the calculations of the population of the water vapor vibrational levels shown here, the algorithm was set to use the lambda iteration technique (López-Puertas and Taylor, 2001) and line-by-line treatment for solving the non-LTE problem. The GRANADA code has been used for the analysis of $\mathrm{CO}_{2}$, $\mathrm{H}_{2} \mathrm{O}, \mathrm{O}_{3}, \mathrm{CH}_{4}, \mathrm{NO}_{2}, \mathrm{NO}$, and $\mathrm{CO}$ emissions measured by the MIPAS instrument on the Envisat satellite (Fisher et al., 2008).

The SOPC non-LTE algorithm, based on the model developed by López-Puertas et al. (1995), uses the Curtis-matrix technique for the radiation transfer calculations (Goody and Young, 1995; López-Puertas and Taylor, 2001). The vibrational level populations are found by solving a sequence of two-level problems starting from lower vibrational levels and moving towards the higher ones. The algorithm is iterative: the populations of all other vibrational levels that enter the balance equation for two selected levels are assumed to be known and updated by iterating the two-level problem sequence. This algorithm was optimized for the SABER data processing (Mertens et al., 2001). The code uses the radiative transfer module described by Marshall et al. (1994) that replaces the computationally intensive line-by-line calculations with pre-computed emissivity tables.

We compared the outputs of three codes using vertical profiles of atmospheric species retrieved from SABER measurements for different seasons as inputs. The water vapor VMR profiles were calculated with the LIMA model (Berger, 2008). For simplicity, the GRANADA and SOPC codes were not modified, and the comparisons were performed using the set of 7 vibrational levels, reaction rates from Table 1, and a fixed quantum yield for the $\mathrm{O}_{2}(1)$ pumping $(\varepsilon=4)$. Later on the SOPC will be modified to include the new set of rates inferred from this work and the vertically varying $\varepsilon$ profile. We believe that these modifications will not change the conclusions we present in this work and will not add to the estimated uncertainties in the SABER $\mathrm{H}_{2} \mathrm{O}$ VMR retrievals. Figure 9a shows the vibrational temperatures of the 010 and 020 levels calculated by three non-LTE codes. For this run we used the model atmosphere described in Sect. 3.1. The vibrational temperatures of the 010 level demonstrate a good agreement, differing by less than $1 \mathrm{~K}$ at altitudes below $95 \mathrm{~km}$ (Fig. 9a, b). The deviation for the second $\nu_{2}$ vibrational level (020) appears to be larger, reaching $3 \mathrm{~K}$ and $1.5 \mathrm{~K}$ at $\sim 75 \mathrm{~km}$ altitude for the ALI-ARMS and GRANADA codes, respectively. These discrepancies in the vibrational temperatures correspond to $\sim 2 \%$ and $\sim 10 \%$ differences in the populations of the 010 and 020 levels, correspondingly, for the SOPC versus ALI-ARMS comparison. For the SOPC versus GRANADA comparison these values are $\sim 2 \%$ and $\sim 5 \%$ respectively. This corresponds to $\sim 2 \%$ difference in the $6.6 \mu \mathrm{m}$ SABER filter bandpass radiances simulated by the operational and research codes. The differences between $\mathrm{H}_{2} \mathrm{O}$ VMR values retrieved with the research and operational codes are shown in Fig. 9c. As one can see, they do not exceed $3 \%$ up to $90 \mathrm{~km}$ altitude and increase at higher altitudes. The latter increase does not affect the retrievals below $90 \mathrm{~km}$ because of negligible $\mathrm{H}_{2} \mathrm{O}$ density at high altitudes.

In summary, the non-LTE research and operational codes show a very good agreement in vibrational level populations and calculated $6.6 \mu \mathrm{m}$ radiances and, consequently, the retrieved SABER $\mathrm{H}_{2} \mathrm{O}$ VMRs. The comparison results suggest that the new $\mathrm{H}_{2} \mathrm{O}$ VMR retrievals in the next release of SABER data will be consistent with the research retrievals discussed in this work. 


\section{Conclusion}

We have described a non-LTE model and algorithm applied to the $\mathrm{H}_{2} \mathrm{O}$ VMR retrieval from the $6.6 \mu \mathrm{m}$ emissions measured by SABER. The numerical experiments showed that the retrieval method provides a stable solution that does not depend on the initial guess profile. The SABER operational code was validated against two research non-LTE codes, and the differences in the simulated radiances at altitudes up to $90 \mathrm{~km}$ were less than $3 \%$.

We have analyzed the sensitivity of $\mathrm{H}_{2} \mathrm{O}$ VMR retrievals to the rate coefficients used in the non-LTE modeling and inferred the deficiencies of the models for the interpretation of the broadband $6.6 \mu \mathrm{m}$ non-LTE emission developed by López-Puertas et al. (1995) and Manuilova et al. (2001). Using the coincident $\mathrm{H}_{2} \mathrm{O}$ density measurements performed by the ACE-FTS occultation instrument, we have found new values for three rates that affect the $\mathrm{H}_{2} \mathrm{O}\left(v_{2}\right)$ populations and have recommended an update to the $\mathrm{H}_{2} \mathrm{O}$ non-LTE model: $k_{V-V}^{*}\{1\}\left(\mathrm{H}_{2} \mathrm{O}-\mathrm{O}_{2}\right)=(1.2+0.4 /-0.1) \times 10^{-12} \mathrm{~cm}^{3} \mathrm{~s}^{-1}$; $k_{V-T}^{*}\{2\}\left(\mathrm{O}_{2}-\mathrm{O}\right)=(3.3 \pm 0.7) \times 10^{-12} \mathrm{~cm}^{3} \mathrm{~s}^{-1}$; $k_{V-T}^{*}\{7,8\}\left(\mathrm{H}_{2} \mathrm{O}-M\right)=(1.4 \pm 0.4) \times k_{V-T}\{7,8\}\left(\mathrm{H}_{2} \mathrm{O}-M\right)$.

Performing the retrievals with the updated model produces the $\mathrm{H}_{2} \mathrm{O}$ VMR distributions similar to those measured by other instruments and predicted by models. The absolute $\mathrm{H}_{2} \mathrm{O}$ VMR values retrieved from SABER at $50.0-85.0 \mathrm{~km}$ altitudes were compared to MLS, HALOE, WVMS, and microwave measurements at $45.0^{\circ} \mathrm{S}, 19.5^{\circ} \mathrm{N}$, and $69.2^{\circ} \mathrm{N}$, and the agreement was good - within the experimental uncertainties of the datasets.

Qualitatively, the latitudinal distribution of SABER $\mathrm{H}_{2} \mathrm{O}$ VMR profiles calculated for four seasons in 2004 and 2007 agrees with climatology. It demonstrates the main features typical for the water vapor distribution in the middle and upper atmosphere: an increase of the $\mathrm{H}_{2} \mathrm{O}$ VMR from the winter hemisphere to the summer hemisphere and the circulation cells in the equatorial and middle latitude regions that are consistent with current understanding of the physics of the region. The approach developed in this work makes it possible to retrieve $\mathrm{H}_{2} \mathrm{O}$ VMR spatial and temporal distributions for the entire SABER mission $\left(\sim 2 \times 10^{6}\right.$ profiles $)$ from 25 January 2002 until present. In the future, we plan to extend the retrieval algorithm to include the nighttime measurements. This will double the number of $\mathrm{H}_{2} \mathrm{O}$ VMR profiles retrieved from SABER and enhance the utility of the dataset.

\section{Appendix A}

Abbreviations

ACE
ALI-ARMS
ALOMAR
ASTRO-SPAS
ATMOS

Atmospheric Chemistry Experiment Accelerated Lambda Iterations for Atmospheric Radiation and Molecular Spectra

Arctic Lidar Observatory for Middle Atmosphere Research

ATMOS

BANDPAK software PAcKage for calculating the

Astronomical Shuttle-Pallet Satellite

Atmospheric Trace MOlecule Spectroscopy radiative transfer in BANDs

CRISTA Cryogenic Infrared Spectrometers and Telescopes for the Atmosphere, the instrument on board of the ASTROSPAS satellite

FTS

GRANADA

Fourier-Transform Spectrometer

HALOE

Generic RAdiative traNsfer AnD nonLTE population Algorithm

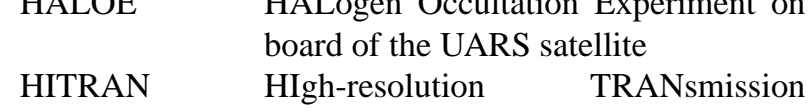
molecular absorption database

KOPRA Karlsruhe Optimized and Precise Radiative transfer Algorithm

LIMA

LIMS

LTE

MIPAS

MLT

NLC

PMSE

RT

SABER

SAMS

SCISAT1

SMR

SNR

SOFIE

SOPC

TIMED

UARS

VMR

WVMS
Leibniz-Institute Middle Atmosphere

Limb Infrared Monitor of the Stratosphere

Local Thermodynamic Equilibrium

Michelson Interferometer for Passive Atmospheric Sounding

Mesosphere/Lower Thermosphere

Noctilucent Cloud

Polar Mesospheric Summer Echoe

Radiative Transfer

Sounding of the Atmosphere using Broadband Emission Radiometry

the Stratospheric And Mesospheric

Sounder

SCIence SATellite 1

Sub-Millimeter Radiometer

Signal to Noise Ratio

Solar Occultation for Ice Experiment

SABER Operational Code

Thermosphere Ionosphere Mesosphere

Energetics and Dynamics

Upper Atmosphere Research Satellite

Volume Mixing Ratio

Water Vapor Mm-wave Spectrometer 
Acknowledgements. This research was supported by NASA grant NNX08AG41G. This work was also partially supported by Spanish MICINN under contract AYA2008-03498/ESP and EC FEDER funds. SABER V1.07 atmospheric data were downloaded from the http://saber.gats-inc.com/ Web site. The authors are grateful to the SABER science, data processing, and flight operations for their ongoing support of this work. The authors also want to thank Gerd Sonnemann and Uwe Berger from the Leibniz Institute for Atmospheric Physics, Kühlungsborn, Germany for the fruitful discussions and assistance in this work. The Atmospheric Chemistry Experiment is a Canadian-led mission mainly supported by the Canadian Space Agency (CSA) and the Natural Sciences and Engineering Research Council of Canada (NSERC). ACE-FTS data were provided by the European Space Agency.

Edited by: W. Ward

\section{References}

Barnet, J. J.: Satellite-borne measurements of middle-atmosphere temperature, Phil. Trans. R. Soc. London, A, 323, 527-544, 1987.

Bass, H. E.: Vibrational relaxation in $\mathrm{CO}_{2} / \mathrm{O}_{2}$ mixtures, J. Chem. Phys., 58(11), 4783-4786, 1973.

Bass, H. E. and Shields, F. D.: Vibrational relaxation and sound absorption in $\mathrm{O}_{2} / \mathrm{H}_{2} \mathrm{O}$ mixtures, J. Acoust. Soc. Am., 56(3), 856859, 1974.

Bass, H. E., Keeton, R. G., and Williams, D.: Vibrational and rotational relaxation in mixtures of water vapor and oxygen, $\mathrm{J}$. Acoust. Soc. Am., 60(1), 74-77, 1976.

Bass, H. E.: Absorption of sound by air: high temperature predictions, J. Acoust. Soc. Am., 69, 124-138, 1981

Berger, U.: Modeling of middle atmosphere dynamics with LIMA, J. Atmos. Solar-Terr. Phy., 1170-1200, doi:10.1016/j.jastp.2008.02.004, 2008.

Bernath, P. F., McElroy, C. T., Abrams, M. C., Boone, C. D., Butler, M., Camy-Peyret, C., Carleer, M., Clerbaux, C., Coheur, P. F., Colin, R., DeCola, P., DeMazière, M., Drummond, J. R., Dufour, D., Evans, W. F. J., Fast, H., Fussen, D., Gilbert, K., Jennings, D. E., Llewellyn, E. J., Lowe, R. P., Mahieu, E., McConnell, J. C., McHugh, M., McLeod, S. D., Michaud, R., Midwinter, C., Nassar, R., Nichitiu, F., Nowlan, C., Rinsland, C. P., Rochon, Y. J., Rowlands, N., Semeniuk, K., Simon, P., Skelton, R., Sloan, J. J., Soucy, M.-A., Strong, K., Tremblay, P., Turnbull, D., Walker, K. A., Walkty, I., Wardle, D. A., Wehrle, V., Zander, R., and Zou, J.: Atmospheric Chemistry Experiment (ACE): Mission overview, Geophys. Res. Lett., 32, L15S01, doi:10.1029/2005GL022386, 2005

Bevilacqua, R. M., Schwartz, P. R., Bologna, J. M., Thacker, D. J., Olivero, J. J., and Gibbins, C. J.: An observational study of water vapor in the mid-latitude mesosphere using ground-based microwave techniques, J. Geophys. Res., 88, 8523-8534, 1983.

Boone, C. D., Nassar, R., Walker, K. A., Rochon, Y., McLeod, S. D., Rinsland, C. P., and Bernath, P. F.: Retrievals for the atmospheric chemistry experiment Fourier-transform spectrometer, Appl. Optics, 44(33), 7218-7231, 2005.

Boone, C. D., Walker, K. A., and Bernath, P. F.: Speed-dependent Voigt profile for water vapor in infrared remote sensing applications, J. Quant. Spectrosc. Ra., 105, 525-532, 2007.
Brasseur, G. P. and Solomon, S.: Aeronomy of the middle atmosphere, Springer, 644 pp, 2005.

Breen, J. E., Quy, R. B., and Glass, G. P.: Vibrational relaxation of $\mathrm{O} 2$ in the presence of atomic oxygen, J. Chem. Phys., 59, 556557, 1973.

Carleer, M. R., Boone, C. D., Walker, K. A., Bernath, P. F., Strong, K., Sica, R. J., Randall, C. E., Vömel, H., Kar, J., Höpfner, M., Milz, M., von Clarmann, T., Kivi, R., Valverde-Canossa, J., Sioris, C. E., Izawa, M. R. M., Dupuy, E., McElroy, C. T., Drummond, J. R., Nowlan, C. R., Zou, J., Nichitiu, F., Lossow, S., Urban, J., Murtagh, D., and Dufour, D. G.: Validation of water vapour profiles from the Atmospheric Chemistry Experiment (ACE), Atmos. Chem. Phys. Discuss., 8, 4499-4559, 2008, http://www.atmos-chem-phys-discuss.net/8/4499/2008/.

Chandra, S., Jackman, C. H., Fleming, E. L., and Russell III, J. M.: The seasonal and long-term changes in mesospheric water vapor, Geophys. Res. Lett., 24(6), 639-642, 1997.

Copeland, R. A.: Measurement of oxygen vibrational relaxation rate constant with oxygen atoms at low temperature, SRI Project P18443, Monthly Report MP 08-067, 2008.

Croom, D. L., Gibbins, C. J., Birks, A. R., and Wrench, C. L.: Ground-based remote sensing of atmospheric $\mathrm{H}_{2} \mathrm{O}$ in the 25 $100 \mathrm{~km}$ region of the atmosphere, in: Union Radio Scientifique Internationale, Open Symposium, La Baule, Loire-Atlantique, France, 28 April-6 May 1977, Proceedings, A78-25801 09-32 Issy-les-Moulineaux, Hauts-de-Seine, France, Comite National Francais de la Radio-electricite Scientifique, 547-550, 1977.

Diskin, G. S., Lempert, W. R., and Miles, R. B.: Observation of vibrational dynamics in $\mathrm{X}^{3} \Sigma_{g}^{-}$-oxygen following stimulated Raman excitation to the $v=1$ level: implications for the RELIEF flow tagging technique; AIAA 96-3001, 34-th Aerospace Sciences Meeting and Exhibit: Reno, NV, 15-18 January 1996.

Drummond, J. R., Houghton, J. T., Peskett, G. D., Rodgers, C. D., Wale, M. J., Whitney, J., and Williamson, E. J.: The Stratospheric and Mesospheric Sounder on Nimbus 7, Philosophical Transactions of the Royal Society of London, Series A, Mathematical and Physical Sciences, 296(1418), The Middle Atmosphere as Observed form Balloons, Rockets and Satellites, 219241, 1980.

Edwards, D. P., Kumer, J. B., López-Puertas, M., Mlynczak, M. G., Gopalan, A., Gille, J. C., and Roche, A.: Non-local thermodynamic equilibrium limb radiance near $10 \mu \mathrm{m}$ as measured by UARS CLAES, J. Geophys. Res., 101(D21) 26577-26588, 1996.

Edwards, D. P., Zaragoza, G., Riese, M., and López-Puertas, M.: Evidence of $\mathrm{H}_{2} \mathrm{O}$ nonlocal thermodynamic equilibrium emission near $6.4 \mu \mathrm{m}$ as measured by cryogenic infrared spectrometers and telescopes for the atmosphere (CRISTA 1), J. Geophys. Res., 105(D23), 29003-29021, 2000.

Esposito, F. and Capitelli, M.: The relaxation of vibrationally excited $\mathrm{O}_{2}$ molecules by atomic oxygen, Chem. Phys. Lett., 443, 222-226, 2007.

Finzi, J., Hovis, F. E., Panfilov, V. N., Hess, P., and Moore, C. B.: Vibrational relaxation of water vapor, J. Chem. Phys., 67(9), 4053-4061, 1977.

Fischer, H., Birk, M., Blom, C., Carli, B., Carlotti, M., von Clarmann, T., Delbouille, L., Dudhia, A., Ehhalt, D., Endemann, M., Flaud, J. M., Gessner, R., Kleinert, A., Koopman, R., Langen, J., López-Puertas, M., Mosner, P., Nett, H., Oelhaf, H., Perron, G., Remedios, J., Ridolfi, M., Stiller, G., and Zander, R.: MIPAS: an 
instrument for atmospheric and climate research, Atmos. Chem. Phys., 8, 2151-2188, 2008,

http://www.atmos-chem-phys.net/8/2151/2008/.

Funke, B., Martin-Torres, F.-J., López-Puertas, M., Hoepfner, M., Hase, F., López-Valverde, M. A., and Garcia-Cómas, M.: A generic non-LTE population model for MIPAS-ENVISAT data analysis, Geophys. Res. Abstr., 4, abstract \#4915, 2002.

Garcia, R. R. and Solomon, S.: A new numerical model of the middle atmosphere. 2. Ozone and related species, J. Geophys. Res., 99(D6), 12937-12951, 1994.

Gille, J. C., Bailey, P. L., and Russell III, J. M.: Temperature and composition measurements from the LRIR and LIMS experiments on Nimbus 6 and 7, Philos. Tr. R. Soc. S.-A., 89, 205-218, 1980.

Gille, J. C. and Russell III, J. M.: The Limb Infrared Monitor of the Stratosphere - Experiment description, performance, and results, J. Geophys. Res., 89(D4), 5125-5140, 1984.

Goody, R. M. and Young, Y. L.: Atmospheric radiation: Theoretical Basis, Oxford University Press, USA, 544 pp, 1995.

Gordley, L. L. and Russell III, J. M.: Rapid inversion of limb radiance using an emissivity growth approximation, Appl. Optics, 20, 807-813, 1981.

Gordley, L. L., Hervig, M., Fish, C., Russell III, J. M., Bailey, S., Cook, J., Hansen, S., Shumway, A., Paxton, G., Deaver, L., Marshall, T., Burton, J., Magill, B., Brown, C., Thompson, E., and Kemp, J.: The Solar Occultation For Ice Experiment (SOFIE), J. Atmos. Solar-Terr. Phys., 71(3-4), 300-315, doi:10.1016/j.jastp.2008.07.012, 2009.

Grossmann, K. U., Offermann, D., Gusev, O., Oberheide, J., Riese, M., and Spang, R.: The CRISTA-2 mission, J. Geophys. Res., 107(D23), 8173-8185, doi:10.1029/2001JD000667, 2002.

Gunson, M. R., Abbas, M. M., Abrams, M. C., Allen, M., Brown, L. R., Brown, T. L., Chang, A. Y., Goldman, A., Irion, F. W., Lowes, L. L., Mahieu, E., Manney, G. L., Michelsen, H. A., Newchurch, M. J., Rinsland, C. P., Salawitch, R. J., Stiller, G. P., Toon, G. C., Yung, Y. L., and Zander, R.: The Atmospheric Trace Molecule Spectroscopy (ATMOS) experiment: Deployment on the ATLAS Space Shuttle missions, Geophys. Res. Lett., 23(17), 2333-2336, doi:10.1029/96GL01569, 1996.

Gusev, O. A.: Non-LTE diagnostics of infrared observations of the planetary atmospheres, $\mathrm{PhD}$ thesis, University of Munich, http: //deposit.ddb.de/cgi-bin/dokserv?idn=968893651\&dok_var= d1\&dok_ext=pdf\&filename=968893651.pdf, 2003.

Gusev, O., Kaufmann, M., Grossmann, K. U., Schmidlin, F. J., and Shepherd, M. G.: Atmospheric neutral temperature distribution at the mesopause/turbopause altitude, J. Atmos. Sol.-Terr. Phy., 68(15), 1684-1697, doi:10.1016/j.jastp.2005.12.010, 2006.

Gusev, O. A. and Kutepov, A. A.: Non-LTE gas in planetary atmospheres, in: book: Stellar Atmosphere Modeling, edited by: Hubeny, I., Mihalas, D., and Werner, K., ASP Conference Series, 288, 318-330, 2003.

Harris, R. D. and Adams, G. W.: Where does the O(1D) energy go?, J. Geophys. Res., 88(A6), 4918-4928, 1983.

Hartogh, P., Jarchow, C., and Song, L.: Ground-based detection of middle atmospheric water vapor, Proc. SPIE, 2586, Global Process Monitoring and Remote Sensing of the Ocean and Sea Ice, edited by: Deering, D. W. and Gudmandsen, P., 188-195, 1995.

Huestis, D. L.: Vibrational energy transfer and relaxation in $\mathrm{O}_{2}$ and
$\mathrm{H}_{2} \mathrm{O}$, J. Phys. Chem. A, 110, 6638-6642, 2006.

Ivanov, M. V., Schinke, R., and Mcbane, G. C.: Theoretical investigation of vibrational relaxation of $\mathrm{NO}\left({ }^{2} \Pi\right), \mathrm{O}_{2}\left({ }^{3} \Sigma_{g}^{-}\right)$, and $\mathrm{N}_{2}\left({ }^{1} \Sigma_{g}^{+}\right)$in collisions with O(3P), Mol. Phys., 105(9), 1183 1191, doi:10.1080/00268970701288087, 2007.

Kalogerakis, K. S., Copeland, R. A., and Slanger, T. G.: Measurements of the rate coefficient for collisional removal of $\mathrm{O}_{2}\left(\mathrm{X}^{3} \Sigma_{g}^{-}, \mathrm{v}=1\right)$ by $\mathrm{O}\left({ }^{3} \mathrm{P}\right)$, J. Chem. Phys., 123, 044309, doi:10.1063/1.2110227, 2005.

Kaufmann, M., Gusev, O. A., Grossmann, K. U., Roble, R. G., Hagan, M. E., Hartsough, C., and Kutepov, A. A.: The vertical and horizontal distribution of $\mathrm{CO}_{2}$ densities in the upper mesosphere and lower thermosphere as measured by CRISTA, J. Geophys. Res., D107, 8182, doi:10.1029/2001JD000704, 2002.

Kaufmann, M., Gusev, O. A., Grossmann, K. U., Martin-Torres, F. J., Marsh, D. R., and Kutepov, A. A.: Satellite observations of day- and nighttime ozone in the mesosphere and lower thermosphere, J. Geophys. Res., 108(D9), 4272, doi:10.1029/2002JD002800, 2003.

Körner, U. and Sonnemann, G. R.: Global three-dimensional modeling of the water vapor concentration of the mesospheremesopause region and implications with respect to the noctilucent cloud region, J. Geophys. Res., 106(9), 9639-9651, 2001.

Kutepov, A. A., Gusev, O. A., and Ogibalov, V. P.: Solution of the non-LTE problem for molecular gas in planetary atmospheres: Superiority of accelerated lambda iteration, J. Quant. Spectrosc. Radiat., 60, 199-220, 1998.

Kutepov, A. A., Feofilov, A. G., Marshall, B. T., Gordley, L. L., Pesnell, W. D., Goldberg, R. A., and Russell III, J. M.: SABER temperature observations in the summer polar mesosphere and lower thermosphere: importance of accounting for the $\mathrm{CO}_{2} \quad v_{2}$-quanta V-V exchange, Geophys. Res. Lett., 33, L21809, doi:10.1029/2006GL026591, 2006.

Lambert, A., Read, W. G., Livesey, N. J., Santee, M. L., Manney, G. L., Froidevaux, L., Wu, D. L., Schwartz, M. J., Pumphrey, H. C., Jimenez, C., Nedoluha, G. E., Cofield, R. E., Cuddy, D. T., Daffer, W. H., Drouin, B. J., Fuller, R. A., Jarnot, R. F., Knosp, B. W., Pickett, H. M., Perun, V. S., Snyder, W. V., Stek, P. C., Thurstans, R. P., Wagner, P. A., Waters, J. W., Jucks, K. W., Toon, G. C., Stachnik, R. A., Bernath, P. F., Boone, C. D., Walker, K. A., Urban, J., Murtagh, D., Elkins, J. W., and Atlas, E.: Validation of the Aura Microwave Limb Sounder middle atmosphere water vapor and nitrous oxide measurements. J. Geophys. Res., 112, D24S36, doi:10.1029/2007JD008724, 2007.

López-Puertas, M., Zaragoza, G., Kerridge, B. J., and Taylor, F. W.: Non-local thermodynamic equilibrium model for $\mathrm{H}_{2} \mathrm{O} 6.3$ and $2.7 \mu \mathrm{m}$ bands in the middle atmosphere, J. Geophys. Res., 100, 9131-9147, 1995.

López-Puertas, M. and Taylor, F. W.: Non-LTE Radiative Transfer in the Atmosphere, World Scientific Publishing Co., River Edge, N.J., 504 pp, 2001.

Lübken, F.-J., Rapp, M., and Strelnikova, I.: The sensitivity of mesospheric ice layers to atmospheric background temperatures and water vapor, Adv. Space Res., 40, 794-801, doi:10.1016/j.asr.2007.01.014, 2007.

Manuilova, R. O., Yankovsky, V. A., Semenov, A. O., Gusev, O. A., Kutepov, A. A., Sulakshina, O. N., and Borkov, Yu. G.: Non-equilibrium emission of the middle atmosphere in the IR 
ro-vibrational water vapor bands, Atmos. Oceanic Opt., 14, 864867,2001

Marshall, B. T. and Gordley, L. L.: BANDPAK: Algorithms for Modeling Broadband Transmission and Radiance, J. Quant. Spectrosc. Radiat., 52(5), 581-599, 1994.

Mertens, C. J., Mlynczak, M. G., López-Puertas, M., Wintersteiner, P.P., Picard, R. H., Winick, J. R., Gordley, L. L., and Russell III, J. M.: Retrieval of mesospheric and lower thermospheric kinetic temperature from measurements of $\mathrm{CO} 215 \mu \mathrm{m}$ Earth limb emission under non-LTE conditions, Geophys. Res. Lett., 28(7), 1391-1394, 2001.

Murtagh, D., Frisk, U., Merino, F., Ridal, M., Jonsson, A., Stegman, J., Witt, G., Eriksson, P., Jimenez, C., Mégie, G., de La Noëë, J., Ricaud, P., Baron, P., Pardo, J.-R., Hauchecorne, A., Llewellyn, E. J., Degenstein, D. A., Gattinger, R. L., Lloyd, N. D., Evans, W. F. J., McDade, I. C., Haley, C., Sioris, C., von Savigny, C., Solheim, B. H., McConnell, J. C., Strong, K., Richardson, E. H., Leppelmeier, G. W., Kyrölä, E., Auvinen, H., and Oikarinen, L.: An overview of the Odin atmospheric mission, Can. J. Phys., 80, 309-319, 2002.

Nedoluha, G. E., Bevilacqua, R. M., Gomez, R. M., Waltman, W. B., and Hicks, B. C.: Measurements of water vapor in the middle atmosphere and implications for mesospheric transport, J. Geophys. Res., 101, 21183-21193, 1996.

Nedoluha, G., Bevilacqua, R., Gomez, R., Waltman, W., Hicks, B., Thacker, D., Russell III, J., Abrams, M., Pumphrey, H., and Connor, B.: A comparative study of mesospheric water vapor measurements from the ground-based water vapor millimeterwave spectrometer and space-based instruments, J. Geophys. Res., 102(D14), 16647-16661, 1997.

Nedoluha, G. E., Bevilacqua, R. M., Gomez, R. M., Siskind, D. E., Hicks, B. C., Russell III, J. M., and Connor, B. J.: Increases in middle atmospheric water vapor as observed by the Halogen Occulation Experiment and the ground-based Water Vapor Millimeter-wave Spectrometer from 1991-1997, J. Geophys. Res., 103, 3531-3543, 1998.

Nedoluha, G. E., Gomez, R. M., Hicks, B. C., Bevilacqua, R. M., Russell III, J. M., Connor, B. J., and Lambert, A.: A comparison of middle atmospheric water vapor as measured by WVMS, EOS-MLS, and HALOE, J. Geophys. Res., 112, D24S39, doi:10.1029/2007JD008757, 2007.

Offermann, D., Grossmann, K. U., Barthol, P., Knieling, P., Riese, M., and Trant, R.: Cryogenic Infrared Spectrometers and Telescopes for the Atmosphere (CRISTA) experiment and middle atmosphere variability, J. Geophys. Res., 104, 16311-16325, 1999.

Petelina, S. V. and Zasetsky, A. Y.: Temperature of mesospheric ice retrieved from the O-H stretch band, Geophys. Res. Lett., 36, L15804, doi:10.1029/2009GL038488, 2009.

Peter, R.: Stratospheric and mesospheric latitudinal water vapor distributions obtained by an airborne millimeter-wave spectrometer, J. Geophys. Res., 103(D13), 16275-16290, 1998.

Press, W. H., Teukolsky, S. A., Vetterling, W. T., and Flannery, B. P.: Numerical Recipes in $\mathrm{C}++$, The Art of Scientific Computing, Second Edition, Cambridge University Press, 1002 pp, 2002.

Rapp, M. and Thomas, G.: Modeling the microphysics of mesospheric ice particles: Assessment of current capabilities and basic sensitivities, J. Atmos. Solar-Terr. Phys., 68(7), 715-744, 2006.

Remsberg, E. E., Marshall, B. T., Garcia-Comas, M., Krueger, D.,
Lingenfelser, G. S., Martin-Torres, J., Mlynczak, M. G., Russell, J. M., Smith, A. K., Zhao, Y., Brown, C., Gordley, L. L., LopezGonzalez, M. J., Lopez-Puertas, M., She, C.-Y., Taylor, M. J., and Thompson, R. E.: Assessment of the quality of the Version 1.07 temperature-versus-pressure profiles of the middle atmosphere from TIMED/SABER, J. Geophys. Res., 113, D17101, doi:10.1029/2008JD010013, 2008.

Rothman, L. S., Jacquemart, D., Barbe, A., Benner, D. C., Birk, M., Brown, L. R., Carleer, M. R., Chackerian Jr., C., Chance, K., Coudert, L. H., Dana, V., Devi, V. M., Flaud, J.-M., Gamache, R. R., Goldman, A., Hartmann, J.-M., Jucks, K. W., Maki, A. G., Mandin, J.-Y., Massie, S. T., Orphal, J., Perrin, A., Rinsland, C. P., Smith, M. A. H., Tennyson, J., Tolchenov, R. N., Toth, R. A., Vander, J., Auwera, Varanasi, P., and Wagner, G.: The HITRAN 2004 molecular spectroscopic database, J. Quant. Spectrosc. Radiat. Transf., 96, 139-204, 2005.

Russell III, J. M., Gordley, L. L., Park, J. H., Drayson, S. R., Hesketh, D. H., Cicerone, R. J., Tuck, A. F., Frederick, J. E., Harries, J. E., and Crutzen, P. J.: The Halogen Occultation Experiment, J. Geophys. Res., 98(D6), 10777-10797, 1993.

Russell III, J. M., Mlynczak, M. G., Gordley, L. L., Tansock, J. J., and Esplin, R. W.: An Overview of the SABER Experiment and Preliminary Calibration Results, SPIE 3756, 277-288, 1999.

Rybicki, G. B. and Hummer, D. G.: An accelerated lambda iteration method for multilevel radiative transfer. I - Non-overlapping lines with background continuum, Astron. Astrophys., 245, 171$181,1991$.

Saran, D. V., Pejakovic, D. A., and Copeland, R. A.: Vibrational Relaxation of Ground-State Oxygen Molecules With Atomic Oxygen and Carbon Dioxide, AGU Fall Meeting, San Francisco, California, USA, 15-19 December 2008, Abstract SA31A-1601, 2008.

She, C. Y. and von Zahn, U.: Concept of a two-level mesopause: Support through new lidar observations, J. Geophys. Res., 103, 5855-5863, 1998.

Siskind, D. E., Stevens, M. H., Emmert, J. T., Drob, D. P., Kochenash, A. J., Russell, J. M., Gordley, L. L., and Mlynczak, M. G.: Signatures of shuttle and rocket exhaust plumes in TIMED/SABER radiance data, Geophys. Res. Lett., 30(15), 1819, doi:10.1029/2003GL017627, 2003.

Sonnemann, G. R., Grygalashvyly, M., and Berger, U.: Autocatalytic water vapor production as a source of large mixing ratios within the middle to upper mesosphere, J. Geophys. Res., 110, D15303, doi:10.1029/2004JD005593, 2005.

Sonnemann, G. R., Hartogh, P., Li, S., Grygalashvyly, M., and Berger, U.: A QBO-signal in mesospheric water vapor measurements at ALOMAR $\left(69.29^{\circ} \mathrm{N}, 16.03^{\circ} \mathrm{E}\right)$ and in model calculations by LIMA over a solar cycle, Atmos. Chem. Phys. Discuss., 9, 883-903, 2009,

http://www.atmos-chem-phys-discuss.net/9/883/2009/.

Stevens, M. H., Gumbel, J., Englert, C. R., Grossmann, K. U., Rapp, M., and Hartogh, P.: Polar mesospheric clouds formed from space shuttle exhaust, Geophys. Res. Lett., 30(10), 1546, doi:10.1029/2003GL017249, 2003.

Stevens, M. H., Meier, R. R., Chu, X., DeLand, M. T., and Plane, J. M. C.: Antarctic mesospheric clouds formed from space shuttle exhaust, Geophys. Res. Lett., 32, L13810, doi:10.1029/2005GL023054, 2005.

Stiller, G. P. (Ed.), with contributions from v. Clarmann, T., Dud- 
hia, A., Echle, G., Funke, B., Glatthor, N., Hase, F., Höpfner, M., Kellmann, S., Kemnitzer, H., Kuntz, M., Linden, A., Linder, M., Stiller, G. P., and Zorn, S.: The Karlsruhe Optimized and Precise Radiative transfer Algorithm (KOPRA), Forschungszentrum Karlsruhe, Wissenschaftliche Berichte, Bericht Nr. 6487, http://www-imk.fzk.de/asf/ame/publications/kopra_docu/, 2000.

Tachikawa, H., Hamabayashi, T., and Yoshida, H.: Electronic-toVibrational and -Rotational Energy Transfer in the $\mathrm{O}\left({ }^{1} \mathrm{D}\right)+\mathrm{N}_{2}$ Quenching Reaction: Ab Initio MO and Surface-Hopping Trajectory Studies, J. Phys. Chem., 99, 16630-16635, 1995.

Taylor, F. W., Rodgers, C. D., Whitney, J. G., Werrett, S. T., Barnett, J. J., Peskett, G. D., Venters, P., Ballard, J., Palmer, C. W. P., Knight, R. J., Morris, P., Nightingale, T., and Dudhia, A.: Remote sensing of the atmospheric structure and composition by pressure modulator radiometry from space: the ISAMS experiment on UARS, J. Geophys. Res., 98(D6), 10799-10814, doi:10.1029/92JD03029, 1993.

Thomas, G. E.: Are noctilucent clouds harbingers of global change in the middle atmosphere?, Adv. Space Res., 32(9), 1737-1746, 2003.

Waters, J. W., Read, W. G., Froidevaux, L., Jarnot, R. F., Cofield, R. E., Flower, D. A., Lau, G. K., Pickett, H. M., Santee, M. L., Wu, D. L., Boyles, M. A., Burke, J. R., Lay, R. R., Loo, M. S., Livesey, N. J., Lungu, T. A., Manney, G. L., Nakamura, L. L., Perun, V. S., Ridenoure, B. P., Shippony, Z., Siegel, P. H., and Thurstans, R. P.: The UARS and EOS Microwave Limb Sounder (MLS) Experiments, J. Atmos. Sci., 56(2), 194-218, doi:10.1175/1520-0469, 1999.

Whitson, M. E. and McNeal, R. J.: Temperature dependence of the quenching of vibrationally excited $\mathrm{N}_{2}$ by $\mathrm{NO}$ and $\mathrm{H}_{2} \mathrm{O}$, J. Chem. Phys. 66(6), 2696-2700, doi:10.1063/1.434217, 1977.
Yankovsky, V. A. and Manuilova, R. O.: Model of daytime emissions of electronically-vibrationally excited products of $\mathrm{O}_{3}$ and $\mathrm{O}_{2}$ photolysis: application to ozone retrieval, Ann. Geophys., 24, 2823-2839, 2006, http://www.ann-geophys.net/24/2823/2006/.

Yankovsky, V. A. and Babaev, A. S.: Specified calculation of the distribution of molecules of $\mathrm{O}_{2}(\mathrm{X}, \mathrm{v}=1-30)$ in the mesosphere using new data on the quenching rate constant of reaction $\mathrm{O}_{2}(\mathrm{X}$, v) with atomic oxygen, Atmos. Oceanic Optics, accepted, 2009 (in Russian).

Yee, J.-H., Cameron, G. E., and Kusnierkiewicz, D. Y.: Overview of TIMED, SPIE, 3756, 244-254, 1999.

Zahr, G. E., Preston, R. K., and Miller, W. H.: Theoretical treatment of quenching in $\mathrm{O}\left({ }^{1} \mathrm{D}\right)+\mathrm{N}_{2}$ collisions, J. Chem. Phys., 62(3), 1127-1135, 1975.

Zaragoza, G., López-Puertas, M., Lambert, A., Remedios, J. J., and Taylor, F. W.: Non-local thermodynamic equilibrium in $\mathrm{H} 2 \mathrm{O} 6.9 \mu \mathrm{m}$ emission as measured by the improved stratospheric and mesospheric sounder, J. Geophys. Res., 103(D23), 3129331308, 1998.

Zhou, D. K., Mlynczak, M. G., López-Puertas, M., and Zaragoza, G.: Evidence of Non-LTE Effects in Mesospheric Water Vapor from Spectrally-Resolved Emissions Observed by CIRRIS-1A, Geophys. Res. Lett., 26(1), 67-70, 1999.

Zittel, P. F. and Masturzo, D. E.: Vibrational relaxation of $\mathrm{H}_{2} \mathrm{O}$ from 295 to 1020 K, J. Chem. Phys., 90(2), 977-989, 1989. 